\title{
Site-Specific Catalytic Activity of a Platinum Surfaces Model in Different Electrolytic Environments as Monitored by the CO Oxidation Reaction
}

\author{
Manuel J. S. Farias ${ }^{1,{ }^{*}}$, Gisele A. B. Mello ${ }^{2}$, Auro A. Tanaka ${ }^{1}$, Juan M. Feliu ${ }^{2}$ \\ ${ }^{1}$ Departamento de Química, Universidade Federal do Maranhão, \\ Avenida dos Portugueses, 1966, CEP 65080-805, São Luís - MA, Brazil \\ ${ }^{2}$ Instituto de Electroquímica, Universidad de Alicante, \\ Apartado 99, 03080 Alicante, Spain
}

\begin{abstract}
Stepped Pt surfaces having different width (111) terraces interrupted by (110) or (100) monoatomic steps were employed to evaluate the catalytic activity towards $\mathrm{CO}$ oxidation at specific sites of these surfaces in $\mathrm{HClO}_{4}, \mathrm{H}_{2} \mathrm{SO}_{4}$, and $\mathrm{H}_{3} \mathrm{PO}_{4}$ solutions, as well as in phosphate buffer and alkaline solution. The catalytic activity at the (111) terraces was sensitive to the nature of the anions derived from the electrolyte dissociation, while no effect on catalytic activity was detected at the monoatomic steps. For the same stepped surface, a change in solution $\mathrm{pH}$, passing from acid to alkaline solutions, had contrasting effects on catalytic activity at the (111) terraces and the step sites, with the catalytic activity of the (111) terraces improving, while catalytic activity at the step sites deteriorated. It was found that the release of CO surface sites occurred preferentially from the (111) terraces of the $\operatorname{Pt}(\mathrm{s})-[(n-1)(111) \times(110)]$ series, while from $\operatorname{Pt}(\mathrm{s})$ $[(n)(111) \times(100)]$ surfaces, (111) terrace and (100) step sites were released simultaneously.
\end{abstract}

Keywords: Electrocatalysis, surface structure-sensitive, anions adsorption, active sites, CO electro-oxidation.

*Author to whom correspondence should be addressed: manueljsfarias@gmail.com (M.J.S. Farias); Phone: +55 9833018246. 


\section{Introduction}

In heterogeneous (electro)catalysis, reactions that are surface structure-sensitive are conceived as a class of reactions whose catalytic performance (in terms of reactivity, activity, selectivity, and stability) depend on the geometric configurations of the exposed atoms on the catalyst surfaces ${ }^{1-4}$. Catalytic activity and selectivity are properties which, to some extent, are influenced by competition of species for surface sites, and can also depend on the relative strengths of binding between surface sites and different species in the reaction environment ${ }^{5,6}$. In the case of a metal|electrolyte solution interface, it is reasonable to assume that in an aqueous electrochemical environment, some of the species involved in a catalyzed reaction compete for the same surface sites that may also be disputed by species derived from dissociation of the electrolyte, especially those anions that have affinity for binding with the active sites. Moreover, the interaction of anions with active sites on Pt electrodes is expected to depend on many factors, including the electrode potential window and the nature of the exposed faces of the electrodes ${ }^{7-12}$. Characterization of these active sites (such as terraces and steps), whose interaction with anions affects the catalytic activity of the surface, is of great relevance because this type of information should be considered in the description of the origins of surface structure sensitivity that some reactions present in electrocatalysis. Moreover, the solution $\mathrm{pH}$ can also influence the catalytic performance of an electrode, but the mechanism whereby it affects (improves or inhibits) the catalytic activity of sites at different locations on the surface of the same catalyst has not been established. This can be achieved using wellordered catalyst surfaces and the simplest possible structure sensitive reactions, such as the electro-oxidation reaction of $\mathrm{CO}$ on stepped Pt surfaces performed using a wide range of $\mathrm{pH}$ values.

Three kinds of acid electrolytes are typically used in half-cells in electrocatalytic studies. The most important are those based on perchlorate and sulfate solutions, while phosphate-based solutions are used less frequently. Perchlorate anions $\left(\mathrm{ClO}_{4}^{-}\right)$have traditionally been conceived to adsorb weakly on Pt surfaces, but claims have been made that they specifically adsorb on (111) planes of $\mathrm{Pt},{ }^{13-15}$ as well as on polycrystalline $\mathrm{Pt}^{16}$. In a study of the influence of perchlorate concentration on the voltammetric profiles of a Pt single crystal in $\mathrm{HClO}_{4}$ solutions, Attard et al. ${ }^{15}$ suggested that perchlorate adsorbed more strongly on (111) planes than on (110) domains, and also concluded that the anions did not adsorb on the (100) plane. Sawatari et al. ${ }^{14}$ suggested that perchlorate presents a threefold coordination on the (111) plane of Pt. Meanwhile, anions derived from the 
dissociation of sulfuric acid have been found to show strong adsorption, hence competing for the active sites on the catalyst surface ${ }^{17}$. Nart et al. ${ }^{18-21}$, using vibrational spectroscopy, surface selection rules, and group theory, proposed that the adsorbed species from sulfuric acid dissociation was the sulfate anion. After a long debate about the chemical nature of the adsorbed species generated from sulfuric acid solutions, consistent data from radiotracer $^{22}$ and STM ${ }^{8 \text { (and reference therein) }}$ techniques, as well as thermodynamic analyses ${ }^{23}$, support sulfate as the most likely candidate for the identified adsorbate with $\sim 0.2$ maximum coverage, in agreement with SNIFTIR $^{24}$ studies. The exact nature of this species, however, would have no influence in the present study, only the fact that specific anion adsorption takes place.

The adsorption strength of $\mathrm{ClO}_{4}^{-}$is weaker, compared to that of $\mathrm{SO}_{4}^{2-16,25,26}$, and anions from phosphoric acid dissociation are generally considered to adsorb more strongly than the two other anions ${ }^{25}$. The process of adsorption of anions such as $\mathrm{SO}_{4}^{2-}$ and $\mathrm{HPO}_{4}^{2-}$ (hydrogen phosphate) becomes more thermodynamically favorable (considering the Gibbs free energy) with increase of potential up to $\sim 0.72-0.78 \mathrm{~V} v s$. $\mathrm{RHE} / \mathrm{V}^{27,28}$. In fact, the nature of the anions present in an electrolyte solution has a strong influence on the potentiodynamic profile of an electrode, with the voltammetric response of a Pt single crystal in perchloric acid solution being markedly different to that recorded in a sulfuric acid solution ${ }^{29}$. As an example, for the vicinal stepped surfaces of $\operatorname{Pt}(111)$, the results obtained for cyclic voltammetry in sulfuric solution were notably different to those recorded in perchloric acid (especially at potentials above $\sim 0.4 v s$. RHE/V) ${ }^{29}$, due to anion adsorption. However, the adsorption strength of these anions is insufficient to affect the surface coverage of an adsorbate such as $\mathrm{CO}$ on Pt electrodes. For example, in terms of the reactivity of a $\mathrm{Pt}(111)$ surface for the adsorption of a $\mathrm{CO}$ adlayer, the surface coverage of $\mathrm{CO}$ is $\sim 0.7$, irrespective of the solution (perchloric acid or sulfuric acid). However, in the case of catalytic activity towards CO oxidation, Herrero et al. ${ }^{30}$ found that at $\sim 300 \mathrm{~K}$, the main oxidation peak for $\mathrm{CO}$ at a Pt(111) electrode was $\sim 120 \mathrm{mV}$ lower in a $0.1 \mathrm{M} \mathrm{HClO}_{4}$ solution than in a $0.5 \mathrm{M} \mathrm{H}_{2} \mathrm{SO}_{4}$ solution. The chemical nature of the anions in the electrolyte seems to introduce a new component to structure sensitivity for $\mathrm{CO}$ oxidation on a similar surface, with the quality of the surface orientation and the clarity of the solution being extremely important considerations. Additionally, even in the case of a strongly poisoning anion, such as chloride, Cuesta et al. ${ }^{31,32}$ observed that the amount of chloride (ranging from $10^{-7}$ to $0.1 \mathrm{M}$ ) in $0.1 \mathrm{M} \mathrm{H}_{2} \mathrm{SO}_{4}$ solution did not affect $\mathrm{CO}$ coverage on $\mathrm{Pt}$, and proposed that even strongly adsorbing anions do not form a 
compact mixed layer with CO. In light of these data reflecting the different adsorption strengths of $\mathrm{ClO}_{4}^{-}, \mathrm{SO}_{4}^{2-}$, and $\mathrm{HPO}_{4}^{2-}$ (the probable ion obtained from dissociation of phosphate-based solutions $)^{28}$, different impacts on catalytic activity would be expected at the various sites on the catalyst surface.

Another factor that can strongly influence the catalytic activity of $\mathrm{Pt}$ is the $\mathrm{pH}$ of the solution. The solution $\mathrm{pH}$ affects the structure of the electrified interface and the charge distribution at the interface, as well as the distribution of species in contact with the metal surface ${ }^{33,34}$. Studies by Couto et al. ${ }^{35}$ (concerning polycrystalline Pt surfaces) and Gisbert et al. ${ }^{36}$ (concerning basal planes and polyoriented Pt surfaces) showed that changing the $\mathrm{pH}$ of the solution from acid to alkaline conditions was accompanied by substantial increases in the catalytic activity of Pt towards the electrooxidation of CO. Spendelow et al. ${ }^{37}$ proposed that higher catalytic activity of $\mathrm{Pt}$ in the oxidation of $\mathrm{CO}$ in alkaline media could be due to the higher affinity of $\mathrm{Pt}(111)$ for the adsorption of hydroxyl species $\left(\mathrm{OH}_{\mathrm{ads}}\right)$, at low potentials, compared to $\mathrm{Pt}$ in acid media. Evidence has been found that a surface defect may promote this reaction in alkaline solution ${ }^{37,38}$. Various sites on Pt surfaces have been suggested as being most active for preferential CO oxidation, ranging from the oxidation of $\mathrm{CO}$ on top of the steps (and kinks) ${ }^{4,39-41}$ to oxidation of those molecules of $\mathrm{CO}$ approaching the step from the lower side ${ }^{42}$. This would imply that during the course of the stripping of a $\mathrm{CO}$ adlayer (in which all the $\mathrm{CO}$ present is attached at the electrode surface), adsorbed CO molecules would shift towards the most active sites, which seems not to be the case ${ }^{43,44}$. The active sites were identified along the (111) terraces, even on kinked Pt surfaces, in both alkaline and acid solutions ${ }^{43,44}$, in agreement with models indicating that the less active sites lie at the top of the steps ${ }^{42,44}$. The main difference between these models is related to the mobility of $\mathrm{CO}$ during its oxidation. It was proposed that in an alkaline solution, with carbonate being the final product of $\mathrm{CO}$ oxidation, the carbonate adsorbs on the electrode surface and blocks the access of $\mathrm{CO}$ from the (111) terraces to the most active sites, which were assigned as step/kink sites ${ }^{4}$, 45. This situation could explain possible oxidation of CO over the (111) terraces. For different reasons, the mobility of $\mathrm{CO}$ on $\mathrm{Pt}$ in alkaline media was considered negligible, with slow availability of active $\operatorname{sites}^{39}$ (due to the specific adsorption of carbonate ${ }^{4,45}$ ), or that it behaved like an immobile species as a consequence of an unfavorable energy gradient along the (111) terraces of stepped Pt surfaces. ${ }^{44}$ It is evident from these studies that there are large differences in the catalytic activity of $\mathrm{Pt}$ for $\mathrm{CO}$ oxidation reactions in acid or alkaline solutions. In alkaline solution, cyclic voltammetry studies have shown 
that increases in the catalytic activity of (111) terraces are always separated (by hundreds of millivolts) from the signatures attributed to $\mathrm{CO}$ oxidation at low coordinated sites. Elucidation of the factors underlying this phenomenon is important for better understanding of the electrocatalytic reaction.

In this contribution, we examine the effects of the oxyanions $\mathrm{ClO}_{4}^{-}$and $\mathrm{SO}_{4}^{2-}$ (both in low $\mathrm{pH}$ solutions) and those from the phosphate-based solution (low $\mathrm{pH}$ and $\mathrm{pH}$ 7.65) on the catalytic activity of well-ordered Pt surfaces towards the $\mathrm{CO}$ oxidation reaction at specific sites, namely (111) terraces and (110) or (100) steps of these surfaces. The findings were compared with the results obtained for similar surfaces in $0.1 \mathrm{M} \mathrm{NaOH}$ solution. We have experimentally determined how the solution $\mathrm{pH}$ can be used to tune the performance of active sites located at different facets of a Pt catalyst surface. Evaluation was also made of the impact of chloride ions on catalytic activity at specific Pt sites for $\mathrm{CO}$ oxidation in a sulfuric acid solution.

\section{Experimental}

The working electrodes used in this study were stepped Pt single crystals, namely $\operatorname{Pt}(554), \operatorname{Pt}(544), \operatorname{Pt}(332)$, and $\operatorname{Pt}(322)$, with geometric areas ranging between $\sim 3$ and $\sim 5$ $\mathrm{mm}^{2}$. The Pt crystal electrodes were prepared according to the procedure described by Clavilier et al. ${ }^{46}$. Hard sphere models for two stepped surfaces are presented in Figure 1. The electrode surfaces employed in this work consisted of (111) terraces, $n$ atoms wide, which were periodically interrupted by (110) or (100) monoatomic steps. Consequently, the surfaces contained crystalline imperfections within the $x-y$ plane of (111) symmetry, which in this case were steps with (110) or (100) orientations. These types of surfaces are obtained by cutting the crystal at a small angle away from the (111) plane along the zone line of the steps with (110) or (100) orientations. According to the Lang-Joyner-Somorjai $(\mathrm{LJS})^{47}$ model, the configuration of these stepped Pt surfaces can be denoted as $\operatorname{Pt}(\mathrm{s})-[(n-$ 1)(111) $\times(110)]$, with Miller index of $(n, n, n-2)$, and $\operatorname{Pt}(\mathrm{s})-[(n-1)(111) \times(100)]$, with Miller index of $(n+1, n-1, n-1)$, for the surfaces with (111) terraces interrupted by (110) and (100) steps, respectively. The local point where an atomic layer of (111) orientation is broken and continues in a similar (111) plane forms a defect line with (110) (or (111)) or (100) orientation, as shown in Figure 1. It should be noted that we only consider as steps the local combination between two Miller indices, with steps ending in the penultimate row of atoms at (111) terraces, as shown in Figure 1, where in the case of $\operatorname{Pt}(\mathrm{s})-[(n-$ 
$1)(111) \times(110)$ ] surfaces, steps was designed as (110) orientations. From the electrochemical point of view, the local point where the (111) terrace is broken presents a well characterized signature in the voltammogram, which in the region of under potential deposition of hydrogen ( $\mathrm{H}_{\mathrm{UPD}}$ ) is interpreted as a defect at the surface ${ }^{48}$, with the rest of the surface behaving as (111) terraces, which also have a well known signature in the $\mathrm{H}_{\mathrm{UPD}}$ region ${ }^{48}$. On this basis, such stepped surfaces can be individually represented as:

$$
\begin{aligned}
& \operatorname{Pt}(s)-[9(111) \times(110)] \equiv \operatorname{Pt}(554) \\
& \operatorname{Pt}(s)-[9(111) \times(100)] \equiv \operatorname{Pt}(544) \\
& \operatorname{Pt}(s)-[5(111) \times(110)] \equiv \operatorname{Pt}(332) \\
& \operatorname{Pt}(s)-[5(111) \times(100)] \equiv \operatorname{Pt}(322)
\end{aligned}
$$

The treatment of the crystal surface consisted of heating it in a butane/air flame, followed by cooling (in a vase half-filled with ultrapure water) in a controlled $\mathrm{H}_{2} / \mathrm{Ar}$ atmosphere. The Pt crystal was protected with a droplet of water (from the vase) and rapidly transferred to the electrochemical cell. The counter electrode was a platinized Pt wire and the reference electrode was a reversible hydrogen electrode (RHE). Experiments were performed in solutions of $0.1 \mathrm{M} \mathrm{HClO}_{4}$ (Suprapur, Merck) with $\mathrm{pH} 1.2,0.1 \mathrm{M}$ $\mathrm{H}_{2} \mathrm{SO}_{4}$ (Suprapur, Merck) with $\mathrm{pH}$ ??, $0.1 \mathrm{M} \mathrm{H}_{3} \mathrm{PO}_{4}$ (Suprapur, Merck) with $\mathrm{pH}$ ??, $\mathrm{Na}_{2} \mathrm{HPO}_{4}$ and $\mathrm{NaH}_{2} \mathrm{PO}_{4}$ phosphate buffer (trace SELECT ${ }^{\circledR}$, Fluka Analytical) with pH 7.65, and 0.1 M NaOH (Merck) with $\mathrm{pH}$ 13.0, all prepared in ultrapure water (Milli-Q, 18.2 $\mathrm{M} \Omega \mathrm{cm}$ ). Solutions of $10^{-3}$ and $10^{-4} \mathrm{M} \mathrm{NaCl}$ (Suprapur, Merck) were prepared for deliberate contamination of sulfate solutions to investigate the influence of chloride anions in a sulfate solution. The solutions were degassed with $\operatorname{Ar}\left(\mathrm{N} 50, \mathrm{Alpha} \mathrm{Gaz}^{\mathrm{TM}}\right)$. In stripping experiments, $\mathrm{CO}\left(\mathrm{N} 47\right.$, Alpha $\left.\mathrm{Gaz}^{\mathrm{TM}}\right)$ was directly injected through the solution for 5 min, always with the electrode potential fixed at $0.100 \mathrm{~V}$. Non-adsorbed CO was eliminated by bubbling $\operatorname{Ar}\left(\mathrm{N} 50\right.$, Alpha Gaz $\left.{ }^{\mathrm{TM}}\right)$ through the solution for $15 \mathrm{~min}$. Even when a similar time for solution degassing was employed, it was observed that during CO stripping, a small CO oxidation pre-wave always appeared in experiments using alkaline solutions. The following procedure was used for CO stripping at steps. After deposition of a $\mathrm{CO}$ adlayer on the electrode surface and removal of non-adsorbed $\mathrm{CO}$ from the solution, a potentiodynamic sweep was run from $0.1 \mathrm{~V}$ up to an upper potential limit 
(depending on the type of electrode surface), enabling the $\mathrm{CO}$ adlayer to be removed piece-by-piece, and not all at once. At the end, stripping of the CO steps was obtained.

The electrode potentials were controlled using a waveform generator (PARC 175, EG\&G) together with a potentiostat (Amel 551) and a digital recorder (eDAC ED 401). All the experiments were carried out at room temperature $\left(25^{\circ} \mathrm{C}\right)$.

\section{Results}

\subsection{Voltammetric Characterization of Pt Single Crystals in Electrolyte Solutions}

Figure 2 shows the cyclic voltammetry results for the stepped Pt surfaces in the presence of electrolyte. A pair of stepped Pt surfaces $(\operatorname{Pt}(554)$ and $\operatorname{Pt}(544))$ were selected for voltammetric characterizations in acid solution $\left(0.1 \mathrm{H}_{2} \mathrm{SO}_{4}\right.$ (black line) and $0.1 \mathrm{M}$ $\mathrm{HClO}_{4}$ (red line)), phosphate buffer solution (PBS) with pH 7.6 (blue line), and $0.1 \mathrm{M}$ $\mathrm{NaOH}$ (blue line). The voltammetric profiles of surfaces of the $\mathrm{Pt}(\mathrm{s})-[(n-1)(111) \times(110)]$ series in the presence of the same electrolyte showed similar patterns, so for the purposes of this work $\operatorname{Pt}(554)$ or $\operatorname{Pt}(332)$ could be considered as representative of the $\operatorname{Pt}(\mathrm{s})-[(n-$ 1)(111) $\times(110)]$ series. Similar considerations could be inferred for $\operatorname{Pt}(544)$ or $\operatorname{Pt}(322)$ surfaces. Significant deviations were observed for very short (111) terraces. Different upper potential limits were used in the voltammetric procedures, with the aim of preserving the status of the surface in each case, considering the type of surface and the electrolyte employed.

In the case of the experiments in $0.1 \mathrm{H}_{2} \mathrm{SO}_{4}$ and $0.1 \mathrm{M} \mathrm{HClO}_{4}$, the voltammetric profiles for $\mathrm{Pt}(554)$ or $\mathrm{Pt}(332)$ completely overlapped in the hydrogen region (the charges were identical). These voltammograms showed reversible coupled features at $\sim 0.126 \mathrm{~V}$, due to the contributions of hydrogen adsorption/desorption (weakly bonded H) at (110) step sites ${ }^{48}$, presumably at the top of the steps. For these surfaces, the current due to the adsorption/desorption at the (111) terraces included a broad feature below a sharp feature at $\sim 0.126 \mathrm{~V}$. The energy of hydrogen adsorption at Pt strongly depends on the $\mathrm{pH}$ of the electrolyte ${ }^{49}$, and in the case of $\mathrm{Pt}(554)$ in $0.1 \mathrm{M} \mathrm{NaOH}$ solution (olive line), these peaks of weakly bonded $\mathrm{H}$ at (110) step sites were positively shifted to $\sim 0.267 \mathrm{~V}$, implying a change of $\sim 141 \mathrm{mV}$, relative to the value obtained in acid solutions. In phosphate buffer with pH 7.6 (blue line), this peak appeared at a value $(\sim 0.172 \mathrm{~V})$ intermediate between the values obtained for acid and alkaline solutions. However, all the hydrogen adsorption/desorption (HUPD) regions for the $\mathrm{Pt}(554)$ surface were within similar potential 
windows for all solution $\mathrm{pH}$ values (in acid, phosphate buffer, and alkaline solutions), on the reversible hydrogen electrode (RHE) scale, as clearly seen in Figure 2. Based on this, it is reasonable to infer that according to the RHE scale, $\mathrm{H}_{\mathrm{UPD}}$ at (110) steps was more energetically affected by the change in solution $\mathrm{pH}$, compared to HUPD at (111) terraces. For surfaces with (100) steps, such as $\operatorname{Pt}(544)$ and $\operatorname{Pt}(322)$, the pair of peaks due to the hydrogen adsorption/desorption at (100) step sites (strongly bonded H) appeared at $\sim 0.280 \mathrm{~V}$ in an acid solution, with a shift to $\sim 0.422 \mathrm{~V}$ in $0.1 \mathrm{M} \mathrm{NaOH}$ solution, which implied a positive shift of $\sim 142 \mathrm{mV}$. However, in alkaline solution, the peak for the strongly bonded $\mathrm{H}$ at (100) steps appeared in a potential range distant from that attributed to hydrogen adsorption/desorption at (111) terraces. The dependence of the hydrogen desorption peak on solution $\mathrm{pH}$ is actually small, only $\sim 10 \mathrm{mV}_{\mathrm{RHE}} / \mathrm{pH}$ unit ${ }^{50}$, for reasons that are not yet fully understood ${ }^{51}$. As before, the regions of the RHE scale corresponding to hydrogen adsorption/desorption at (111) terraces showed no change, while the process at (100) steps shifted to positive potential values with increasing solution $\mathrm{pH}$. This indicates that changes in the solution $\mathrm{pH}$ had different effects on the energies of hydrogen bonded at low coordinated or (111) terrace sites.

In sulfuric acid solution, the reversible processes at $\sim 0.48$ and $\sim 0.46 \mathrm{~V}$ for $\operatorname{Pt}(554)$ and $\mathrm{Pt}(544)$, respectively, were due to the adsorption/desorption of sulfate at broad (111) terraces $^{52}$. The potentials for these features were strongly dependent on the presence of steps on the (111) terraces. In the case of perchloric acid, a current signal started to increase at potentials above $\sim 0.61 \mathrm{~V}$. For the well-ordered $\mathrm{Pt}(111)$ surface, there was growth of a very narrow reversible signal at $\sim 0.8 \mathrm{~V}$, whose origin remains controversial ${ }^{53}$. The profiles of these voltammograms and their stability over several cycles indicated that the surfaces were highly ordered and that the solution was free of impurities, respectively.

Figure 2 shows a comparison of the cyclic voltammograms recorded in sulfuric acid and perchloric acid solutions, with marked effects of anion adsorption at potentials above 0.37 V. Similar effects were observed for a phosphate buffer solution. In phosphate buffer solution ( $\mathrm{pH} 7.65$ ), the feature at potentials of around 0.4-0.6 V (at $\mathrm{pH}$ ranging from $\sim 6$ to $\sim 11$ ) has been attributed to $\mathrm{HPO}_{4}^{-}$, which adsorbs and deprotonates to form the adsorbed $\mathrm{PO}_{4}^{3-}$ ion ${ }^{54}$. This might explain the feature observed in the voltammogram in the potential range from $\sim 0.48 \mathrm{~V}$ to $\sim 0.68 \mathrm{~V}$ for $\mathrm{Pt}(554)$ or $\mathrm{P}(544)$ in phosphate buffer solution. For the sulfate solution (Figure 2), the voltammetric profile of the Pt crystal indicated almost complete blockage at potentials above $\sim 0.6 \mathrm{~V}$. For $\operatorname{Pt}(111)$ surfaces in 
$0.1 \mathrm{M} \mathrm{H}_{2} \mathrm{SO}_{4}$, it has been estimated that the superstructure of sulfate at potential windows ranging from $\sim 0.49$ to $\sim 0.79 \mathrm{~V}$ varies from 0.2 to $0.33 \mathrm{ML}{ }^{8}$

In Figure 2, an important observation was that the state of hydrogen at (100) steps seemed to be slightly different for the sulfuric acid and perchloric acid solutions. For example, the region for hydrogen adsorption/desorption at (100) step sites on the $\operatorname{Pt}(322)$ surface was extended to a slightly more positive potential in perchloric acid, compared to sulfuric acid solution. The charges (integrated from 0.25 to $0.35 \mathrm{~V}$, without double layer correction) above the peak at $0.280 \mathrm{~V}$ were slightly different, with values of $\sim 77$ and $\sim 87$ $\mu \mathrm{C} \mathrm{cm}^{-2}$ in the perchloric acid and sulfuric acid solutions, respectively. Similar trends in peak intensity can be seen in data reported previously. ${ }^{55}$

\subsection{Influence of the Nature of the Electrolyte on the Catalytic Activity of Stepped Pt Surfaces Towards the Oxidation of a Complete CO Adlayer}

Figure 3 compares the catalytic activities of a series of stepped Pt surfaces towards the oxidation of a complete $\mathrm{CO}$ adlayer in different electrolyte solutions. A general feature to be highlighted is that the peak potentials for $\mathrm{CO}$ oxidation were markedly sensitive to both the nature of the surface and the solution $\mathrm{pH}$. As in the previous blank voltammetry analyses, the presence of $\operatorname{Pt}(554)$ or $\mathrm{Pt}(544)$ surfaces could explain the behavior of the $\operatorname{Pt}(\mathrm{s})-[(n-1)(111) \times(110)]$ and $\operatorname{Pt}(\mathrm{s})-[(n-1)(111) \times(100)]$ series, respectively, as well as the $\mathrm{CO}$ stripping. For example, for $\mathrm{Pt}(554)$ in acid solutions (Figure 3A), the potential of the main CO oxidation peak was lower in perchloric acid (blue line) than in sulfuric acid (olive line). In acid solution, the CO stripping on $\mathrm{Pt}$ stepped surfaces presented a single peak, with a $\mathrm{CO}$ pre-oxidation wave sometimes also appearing, as found elsewhere for $\operatorname{Pt}(\mathrm{s})-[(n-1)(111) \times(110)]$ surfaces in acid solutions ${ }^{43}$. In $0.1 \mathrm{M} \mathrm{HClO}_{4}$ solution, the main $\mathrm{CO}$ oxidation peak appeared at a potential of $\sim 0.763$ $\mathrm{V}$, while in sulfuric acid it appeared at $\sim 0.782 \mathrm{~V}$, in agreement with the findings of Herrero et al. ${ }^{30}$. In the case of $\mathrm{Pt}(332)$, the main $\mathrm{CO}$ oxidation peak potentials were at $\sim 0.731$ and $\sim 0.745 \mathrm{~V}$ for $0.1 \mathrm{M} \mathrm{HClO}_{4}$ and $0.1 \mathrm{M} \mathrm{H}_{2} \mathrm{SO}_{4}$, respectively (Figure 3C). In a $\mathrm{CO}$ stripping experiment employing a $\mathrm{Pt}(332)$ surface in $0.1 \mathrm{M} \mathrm{H}_{3} \mathrm{PO}_{4}$ solution, a single CO oxidation peak appeared at $\sim 0.782 \mathrm{~V}$ (Figure SI1). In the case of surfaces with (100) steps, the shifts in potential of the main $\mathrm{CO}$ oxidation peaks in the different acidic electrolytes were similar to those of the previous surface (Figures 3B and 3D). Unfortunately, in these experiments, a single $\mathrm{CO}$ oxidation peak corresponding to the 
oxidation processes of $\mathrm{CO}$ molecules at all types of surface sites (including terraces, steps, and ad-atoms) was observed, which overlapped in a very narrow potential window.

Increase in the $\mathrm{pH}$ of the solution, passing from acid conditions towards alkaline conditions with high $\mathrm{pH}$ resulted in a large shift in the onset potential for $\mathrm{CO}$ oxidation to lower values, with a shift in the potential of the main $\mathrm{CO}$ oxidation peak to $\sim 0.61 \mathrm{~V}$ in $0.1 \mathrm{M} \mathrm{NaOH}$ for $\mathrm{Pt}(554)$, shown in Figure 3A (black line). Unlike the behavior in acid media, as already reported in the literature ${ }^{39}$, CO stripping employing these types of Pt surfaces in alkaline solutions proceeds with the development of multiple $\mathrm{CO}$ oxidation peaks. The peak at $\sim 0.61 \mathrm{~V}$, corresponding to the oxidation of $\mathrm{CO}$ along the (111) terraces $^{44}$, could also be attributed to the oxidation of CO approaching the step from the bottom side ${ }^{42}$. However, in the alkaline solution, a residual $\mathrm{CO}$ adlayer oxidation occurred at $\sim 0.79 \mathrm{~V}$, involving the oxidation of $\mathrm{CO}$ molecules at (110) step sites of the $\operatorname{Pt}(554)$ surface $^{44}$. At pH 7.65 in phosphate buffer (Figure 3A, red line), all the CO oxidation processes occurred at potentials intermediate between those observed for the acidic and alkaline solutions. Hence, compared to acid solution, a change in solution $\mathrm{pH}$ to 7.65 undoubtedly contributed to improving the catalytic activity of all types of sites on the catalyst surface. Because the charge density for the feature at $\sim 0.72 \mathrm{~V}$ in phosphate buffer solution was visibly larger than that at $\sim 0.79 \mathrm{~V}$ for $0.1 \mathrm{M} \mathrm{NaOH}$, it is reasonable to assume that the oxidation process at $\sim 0.72 \mathrm{~V}$ in phosphate buffer solution was a mixture of oxidation of remaining $\mathrm{CO}$ at (111) terraces and $\mathrm{CO}$ at (110) steps. A study of $\mathrm{CO}$ stripping oxidation on $\mathrm{Pt}(\mathrm{s})-[(n-1)(111) \times(110)]$ in alkaline medium showed a linear trend in peak potential position, with the peak at lower potential increasing and the negative potential shifting with the increase in step density ${ }^{39}$, so that the behavior found for the $\operatorname{Pt}(554)$ surface could be extrapolated to the Pt(332) surface. However, experiments for CO stripping oxidation on $\mathrm{Pt}(332)$ (as well as $\mathrm{Pt}(322)$ ) in phosphate buffer have not been reported in the literature, and here we show this in Figure SI2. For the surfaces with (100) steps, the shift in the $\mathrm{CO}$ oxidation peak as a function of solution $\mathrm{pH}$ was not as clear as the shift observed for the stepped surfaces containing (110) steps, with the peaks for CO oxidation at different sites on surfaces of the $\mathrm{Pt}(\mathrm{s})-[(n-1)(111) \times(100)]$ series appearing within a very narrow potential range. We show an example employing $\operatorname{Pt}(544)$ in $0.1 \mathrm{M}$ $\mathrm{NaOH}$ (Figure 3B, black line), and compare the results with those recorded in phosphate buffer solution (Figure 3B, red line). As reported previously ${ }^{39}$, vicinal $\operatorname{Pt}(111)$ surfaces containing (100) steps are less catalytically active towards $\mathrm{CO}$ oxidation than those containing (110) steps. 


\subsection{Influence of the Nature of the Electrolyte on the Intrinsic Catalytic Activity of Step Sites toward CO Oxidation}

The intrinsic catalytic activity at step sites for the $\mathrm{CO}$ oxidation on a stepped $\mathrm{Pt}$ surface can be defined as the catalytic activity obtained when only step sites are occupied by $\mathrm{CO}$, with the (111) terrace sites being free of $\mathrm{CO}$. In order to obtain $\mathrm{CO}$ only at the steps, we always started from a full $\mathrm{CO}$ adlayer that was partially oxidized by voltammetry involving only $\mathrm{CO}$ at the (111) terraces, while $\mathrm{CO}$ at the steps was maintained intact. This involved selection of an appropriate upper potential limit that allowed the CO adlayer to be slowly stripped from the (111) terrace sites. The catalytic activity of low coordinated sites towards the $\mathrm{CO}$ oxidation was then evaluated in perchoric acid, sulfuric acid, phosphate buffer, and sodium chloride-containing solutions (Figures 4, 5, and 7). For Pt(554), the maximum potential for CO oxidation at (110) step sites was $\sim 0.72 \mathrm{~V}$ in sulfuric acid (Figure 4A), perchloric solution (Figure 4B), and pH 7.65 phosphate buffer (Figure 4C). In the case of $\operatorname{Pt}(544)$ (Figure 4), it is noteworthy that the peak potentials for CO oxidation at only (100) step sites were very similar $(\sim 0.72 \mathrm{~V})$ in the perchoric and sulfuric acid solutions (Figures 4E and 4F) and phosphate buffer (Figure 4G). However, for narrow (111) terraces, such as in the case of $\operatorname{Pt}(322)$, the maximum oxidation peak for $\mathrm{CO}$ oxidation at the steps of this surface occurred at a lower potential of $\sim 0.70 \mathrm{~V}$ (Figure 5), as also found in $\mathrm{pH} 7.65$ phosphate buffer solution (Figure SI2). From these results, it seems that the presence of anions, even from the dissociation of phosphate, did not affect the electrocatalysis of $\mathrm{CO}$ oxidation at low coordinated sites.

For $\mathrm{Pt}(554)$ and $\mathrm{Pt}(544)$ (Figure 4), the use of $0.1 \mathrm{M} \mathrm{NaOH}$ solution resulted in a shift of the peak potential for CO oxidation at (110) steps to $\sim 0.79 \mathrm{~V}$, while at (100) steps it occurred at $\sim 0.78 \mathrm{~V}$, as reported previously ${ }^{44}$. The peak potentials for CO oxidation at steps (when the catalytic activity was evaluated only for $\mathrm{CO}$ at steps) and terraces (taking the $\mathrm{CO}$ oxidation peak at terraces for the oxidation of a complete $\mathrm{CO}$ adlayer), as a

function of $\mathrm{pH}$, are shown in Figure 6. The plot for the peak potential related to the oxidation of $\mathrm{CO}$ along the (111) terraces could be explained by the peak potentials for CO oxidation along the (111) terraces and (110) steps rising separately by hundreds of millivolts in the case of $\mathrm{Pt}(\mathrm{s})-[(n-1)(111) \times(110)]$ surfaces in alkaline solution. The plot in Figure 6 shows that the peak potential for oxidation of $\mathrm{CO}$ at (110) steps remained 
constant (at $\sim 0.72 \mathrm{~V}$ ) over a wide $\mathrm{pH}$ range (from $\sim 1$ to 7.65 ), but shifted to $0.79 \mathrm{~V}$ at around $\mathrm{pH} \mathrm{13,} \mathrm{showing} \mathrm{that} \mathrm{a} \mathrm{change} \mathrm{in} \mathrm{solution} \mathrm{pH}$ from acid to alkaline caused a decrease in catalytic activity at step sites. The shift in potential for CO oxidation at (111) terraces showed a linear relationship with the $\mathrm{pH}$ of the solution, with a slope of $\sim 13$ $\mathrm{mV} / \mathrm{pH}$ unit.

Experiments were also performed in which chloride ions were deliberately added to a sulfuric acid solution (at $10^{-3}-10^{-4} \mathrm{M} \mathrm{Cl}^{-}$). The presence of chloride did not affect the coverage of $\mathrm{CO}$ on $\mathrm{Pt}^{31,32}$, so full coverage of $\mathrm{CO}$ on a stepped $\mathrm{Pt}$ surface was first achieved in the presence of chloride ions in solution by direct injection of a flow of CO through the solution. The non-adsorbed $\mathrm{CO}$ was then removed by bubbling Ar into the solution for $15 \mathrm{~min}$. Finally, the $\mathrm{CO}$ at (111) terrace sites was selectively oxidized, leaving $\mathrm{CO}$ only at the steps. The results for four stepped Pt surfaces are displayed in Figure 7. It can be seen that the presence of chloride in the solution caused a positive shift in the peak potential for CO oxidation at step sites (both (110) and (100) steps).

The results shown in Figure 7 are very different to those shown in Figures 4 and 5, where the anions (from the electrolyte dissociation) did not affect the catalytic activity of the step sites towards $\mathrm{CO}$ oxidation. Moreover, a higher concentration of chloride caused a greater potential shift for $\mathrm{CO}$ oxidation at steps. Experiments were performed for the oxidation of a full CO adlayer on these stepped Pt surfaces (Figure SI3). As reported previously by López-Cudero et al. ${ }^{32}$ for polycrystalline Pt in $0.1 \mathrm{M} \mathrm{H}_{2} \mathrm{SO}_{4}$, the data (Figure SI3) showed that the potential of the main $\mathrm{CO}$ oxidation peak (full $\mathrm{CO}$ adlayer) shifted to more positive values due to the presence of chloride anions in solution (as a function of chloride concentration).

\subsection{Identification of Site Release by Partial CO Adlayer Stripping: Hierarchical and non-Hierarchical Processes}

Figures 8 and 9 show the results of partial CO stripping experiments for $\operatorname{Pt}(332)$, $\operatorname{Pt}(322), \operatorname{Pt}(554)$, and $\mathrm{Pt}(544)$ stepped surfaces in perchloric and sulfuric acid solutions. Full CO adlayers were grown on each single crystal surface by dosing with $\mathrm{CO}$ at 0.10 $\mathrm{V}$. At this potential, anions were not adsorbed and the $\mathrm{CO}$ adlayers could be considered identical. After removal of excess $\mathrm{CO}$ from solution, the $\mathrm{CO}$ adlayer was partially stripped by potentiodynamic sweep (PS) of the electrode potential up to a controlled upper potential limit, from which the potential was stepped back to $0.1 \mathrm{~V}$ at the end of each PS. 
In subsequent cycles, the hydrogen region was scanned in order to observe the active sites that were released in the previous potential cycles. For $\mathrm{Pt}(332)$ in $0.1 \mathrm{M} \mathrm{HClO}_{4}$ (Figure $8 \mathrm{~A}$ ), in the first PS (red line) the potential window was extended to $0.705 \mathrm{~V}$ to avoid immediate removal of the CO adlayer. In the second PS (olive line), it could be seen that only sites assigned as (111) terraces were freed in the previous PS (the first PS). Subsequently, in the third PS (blue line), all the CO at terraces (and a small portion of CO at step sites) was released, so that during the fourth PS only CO at step sites was oxidized, with a maximum peak at $\sim 0.72 \mathrm{~V}$ (magenta line), higher than the onset potential for $\mathrm{CO}$ oxidation at the (111) terraces. A similar pattern of site releases was also observed for $\mathrm{Pt}(554)$ in acid media (Figure 9, discussed below).

In terms of surface site release, the behavior observed for $\mathrm{CO}$ adlayer oxidation on a $\operatorname{Pt}(332)$ surface in sulfuric acid was identical to that observed in perchloric acid (Figure 8B). This is an example of a catalyzed reaction that preferentially takes place at the (111) terraces of this kind of surface. The preferential CO oxidation at the (111) terraces on such stepped Pt surfaces can only be observed in cyclic voltammetry if the CO adlayer is oxidized piece-by-piece, as described above. Since similar behavior was observed for broad $^{43}$ and narrow (111) terraces, it could be concluded that CO oxidation on the $\mathrm{Pt}(\mathrm{s})$ $[(n-1)(111) \times(110)]$ series substrates was favored along the (111) terraces, rather than at (110) step sites.

In the case of the $\operatorname{Pt}(322)$ surface in both perchloric acid and sulfuric acid solutions (Figure $8 \mathrm{C} / \mathrm{D}$ ), the surface site release behavior was very different to that observed for $\operatorname{Pt}(332)$, described above. For this surface, release from the (111) terraces and (100) steps occurred simultaneously. The case of $\mathrm{Pt}(322)$ in $0.1 \mathrm{M} \mathrm{HClO}_{4}$ is considered here (Figure 8C), although a similar analysis could be obtained for $\mathrm{Pt}(544)$ in $0.1 \mathrm{M} \mathrm{H}_{2} \mathrm{SO}_{4}$ (Figure 9). In the first PS (red line), the potential window was limited to $0.75 \mathrm{~V}$, so that only a small fraction of the $\mathrm{CO}$ coverage would be removed. In the next potential cycling (olive line), the sites for hydrogen desorption from the (111) terrace sites were recovered, while a peak at $\sim 0.28 \mathrm{~V}$ was unequivocally assigned to hydrogen desorption from (100) step sites.

Similar to the experiments depicted in Figure 8, experiments were also performed using broader (111) terraces, on $\operatorname{Pt}(554)$ and $\operatorname{Pt}(544)$ in sulfuric acid only. Experiments using $\operatorname{Pt}(554)$ in perchloric acid have already been reported ${ }^{43}$, and the results obtained here for $\operatorname{Pt}(544)$ in the same solution are shown in Figure SI4. As in the case of $\operatorname{Pt}(322)$, it was observed that the (111) terraces and (100) step sites of a $\operatorname{Pt}(544)$ surface were released simultaneously during $\mathrm{CO}$ adlayer oxidation. Since $\mathrm{CO}$ easily displaces adsorbed 
hydrogen from the Pt surfaces (as found in a $\mathrm{CO}$ displacement reaction ${ }^{29}$ ), if $\mathrm{CO}_{\text {ads }}$ at (111) terraces behaved as a highly mobile species during its oxidation (which should only occur at the step sites), step sites should never be freed for hydrogen discharging while there was CO remaining at terraces. At $0.1 \mathrm{~V}$, the (100) step sites remained free of CO during the time required to perform and record a voltammetric cycle $(\sim 5 \mathrm{~s})$, as the remaining adsorbed $\mathrm{CO}$ was an immobile species.

\section{Discussion}

The available evidence indicates that the $\mathrm{CO}$ oxidation reaction is a highly structure-sensitive reaction that can be used to probe the influence of adsorption of anions (derived from the dissociation of perchloric, sulfuric, and phosphoric acids) on the catalytic activity of specific sites of stepped Pt surfaces. The influence of the anions from these acids on the catalytic activity of stepped Pt surfaces seems to depend on the crystallographic orientation of the surface sites (insensitive at steps), as well as on CO adlayer preconditioning (most sensitive at high $\mathrm{CO}$ coverage). As is well known, the electrochemical potentiodynamic behaviors of Pt single crystals are markedly influenced by the nature of the anions present in the electrolyte solution, especially at potentials above the hydrogen region ${ }^{56}$. At potentials above this region, whose delimitation depends on the potential of zero total charge and the type of surface orientation ${ }^{57}$ (around $0.35 v s$. RHE/V for a $\operatorname{Pt}(111)$ surface), anions derived from the dissociation of sulfuric and perchloric acids specifically adsorb on (111) terraces of $\mathrm{Pt}^{8,15,58}$. The order of the peak potentials $\left(E_{p}\right)$ during voltammetric oxidation of a full $\mathrm{CO}$ adlayer in the different acid

solutions was: $E_{p, \mathrm{H}_{3} \mathrm{PO}_{4}}>E_{p, \mathrm{H}_{3} \mathrm{SO}_{4}}>E_{p, \mathrm{HClO}_{4}}$. This order of $E_{p}$ follows the decreasing strength of anion adsorption at the electrode surfaces ${ }^{25}$, with the anions from dissociation of perchloric acid binding more weakly than those from the dissociation of phosphoric acid. Thus, considering that the electro-oxidation of $\mathrm{CO}$ proceeds by means of bimolecular collision between the adsorbed $\mathrm{CO}_{\text {ads }}$ and probably a $\left(\mathrm{H}_{2} \mathrm{O}\right)_{\text {activated }}$ species, according to a Langmuir-Hinshelwood type mechanism, the adsorption of anions is likely to affect the initial steps of water dissociation, at least in the presence of a full CO layer. Hence, competition of the anions with the $\left(\mathrm{H}_{2} \mathrm{O}\right)_{\text {activated }}$ species for the same surface sites might be the cause of the shift in onset potential for oxidation of a complete $\mathrm{CO}$ adlayer. From a thermodynamic point of view, adsorption of anions becomes more favorable (in 
terms of Gibbs free energy $)^{27,28}$ at the potential at which water dissociation at pure Pt occurs (above $\sim 0.7 \mathrm{~V} v s$. RHE).

The contribution of the anions to the stages of $\mathrm{CO}$ oxidation, considered a surface structure-sensitive reaction at $\mathrm{Pt}$ stepped surfaces, was strongly related to the initial conditions under which the oxidation of a $\mathrm{CO}$ adlayer started (Figures 8 and 9), with the sensitivity being most pronounced in the initial stages of oxidation of a surface fully blocked with $\mathrm{CO}$. When a complete $\mathrm{CO}$ adlayer was partially oxidized, oxidation of the remaining CO layer proceeded at (111) terraces, with similar voltammetric patterns (starting at similar potentials) observed for all the acid solutions (Figures 8 and 9). This could be indicative of a weak contribution of anions to $\mathrm{CO}$ oxidation in regimes where the reaction proceeded starting from partial CO coverage, with an apparently large availability of free sites at the (111) terraces. The mechanism by which specific adsorbing anions contribute to a certain surface structure-sensitive reaction on hexagonal closepacked domains is therefore likely to be highly complex.

Based on the results of experiments involving the partial stripping of a full $\mathrm{CO}$ adlayer (Figures 8 and 9), as well as those described previously ${ }^{44}$, it appears that the $\mathrm{CO}$ adlayer preferentially oxidizes at the (111) terraces, while CO oxidation at the (110) steps only occurs when all the CO at (111) terraces has been oxidized ${ }^{43,44}$. The CO oxidation reaction therefore preferentially proceeds at the (111) terraces of $\operatorname{Pt}(\mathrm{s})-[(n-1)(111) \times(110)]$ surfaces, at $\mathrm{pH}$ ranging from $\sim 1$ to $\sim 13$. This sequential site release evidences that the most active sites for $\mathrm{CO}$ oxidation on the $\mathrm{Pt}(\mathrm{s})-[(n-1)(111) \times(110)]$ series are along the (111) terraces, at all $\mathrm{pH}$ values. An exception to this is $\mathrm{CO}$ oxidation at surfaces of the $\mathrm{Pt}(\mathrm{s})-[(n-1)(111) \times(100)]$ series in acid media, where CO is oxidized in parallel on (111) terrace and (100) step sites. Steps and terraces have different properties. It has been proposed that the higher catalytic activity at the (111) terraces, compared to the steps of these stepped surfaces, might be related to the electronic perturbation caused by the dipole associated with the steps. Steps and terraces have different reactivity, and the adsorption energy of $\mathrm{CO}$ on low coordinated sites is much higher than on terrace sites ${ }^{59-62}$. In fact, we have observed experimentally that at stepped Pt surfaces in electrochemical environments, $\mathrm{CO}$ firstly fills the steps, followed by the (111) terraces ${ }^{44,63}$. The gradual and hierarchical blockage of surface sites is indicative of a varying energy of interaction over the surface ${ }^{44}$. For the $\operatorname{Pt}(\mathrm{s})-[(n-1)(111) \times(110)]$ stepped surfaces, such electronic perturbation has been linked to the Smoluchowski effect ${ }^{64,65}$, according to which there is a redistribution of surface charge at steps, with a lower $d$-electronic density at the upper 
part of the steps and accumulation of charge density at the bottom of the steps. The upper parts of the steps are sites that firstly fill with CO, while sites at the (111) terraces are the sites with lower reactivity (lower sticking coefficient). Interestingly, the sequence of surface site release due to the $\mathrm{CO}$ electro-oxidation is the opposite of that for surface site occupancy ${ }^{44}$. However, the insertion of (100) steps on (111) terraces, as for the $\operatorname{Pt}(\mathrm{s})-[(n-$ $1)(111) \times(100)]$ stepped surfaces, resulted in different behavior for the release of sites during CO oxidation on these surfaces, with the (111) terraces and (100) steps being released simultaneously or with parallel releases (Figures 8 and 9). This evidenced that CO oxidation on $\operatorname{Pt}(s)-[(n-1)(111) \times(100)]$ stepped surfaces did not preferentially occur along the (111) terrace sites. An experiment previously reported by Busó-Rogero et al. ${ }^{66}$ showed that CO was not preferentially oxidized at the (111) terraces on a $\operatorname{Pt}(544)$ surface in $0.5 \mathrm{M} \mathrm{H}_{2} \mathrm{SO}_{4}$. We found that the decrease in preferential release of (111) terraces was most pronounced for the narrower (111) terraces of the $\operatorname{Pt}(\mathrm{s})-[(n-1)(111) \times(100)]$ stepped surfaces. It seems that a Smoluchowski effect is unable to provide a plausible explanation of the phenomena affecting the catalytic activity of these types of surfaces in acid solution. In addition, the analysis of sites release in the case of $\mathrm{Pt}(\mathrm{s})-[(n-1)(111) \times(100)]$ surfaces in acid solutions suggested that after the step sites became free in previous cycles, they were not occupied by the remaining $\mathrm{CO}$ molecules on the electrode surface on the time scale $(\sim 5 \mathrm{~s})$ between successive cycles, as the remaining adsorbed $\mathrm{CO}$ was an immobile species. This is a strong indication that the mobility of adsorbed $\mathrm{CO}$ might be too slow during its own oxidation.

Evaluation was made of the intrinsic catalytic activity of low coordinated sites, specifically the (110) and (100) step orientations. The potentials for the main CO oxidation peak at steps of the same surface were virtually identical in all the acid solutions and phosphate buffer solution, suggesting that even strongly adsorbing anions such as sulfate or phosphate did not make any contribution to the $\mathrm{CO}$ oxidation at step sites as a structure-sensitive reaction. This raises the question of whether the reaction proceeds via a Langmuir-Hinshelwood or an Eley-Rideal mechanism. Given the assumption that the CO oxidation at step sites proceeds according to the Langmuir-Hinshelwood mechanism, this indicates that anions derived from the dissociation of perchloric, sulfuric, or phosphoric acids did not specifically adsorb on (110) or (100) steps, at least at the potential at which $\mathrm{CO}$ oxidation occurred at these sites $(\sim 0.7 \mathrm{~V})$. If the anions adsorbed at low coordinated sites of $\mathrm{Pt}$, the interactions between them and the surface sites must have been too weak to have any impact on the kinetics of $\mathrm{CO}$ oxidation at such sites. 
Hence, it is likely that there was no barrier to the activation/dissociation of water related to adsorption of the anions at step sites, under this $\mathrm{CO}$ surface coverage condition. However, chloride anions seemed to have a direct interaction with low coordinated sites, such as (110) and (100) steps (Figure 7), and consequently to influence the overpotential for $\mathrm{CO}$ oxidation at the sites where the reaction occurred. This indirectly suggests that the $\mathrm{CO}$ oxidation reaction on low coordinated sites may proceed according to the LangmuirHinshelwood mechanism, rather than the Eley-Rideal mechanism. A similar argument can be applied to the data shown in Figure SI5 (higher onset potential for partial CO adlayer stripping in an electrolyte containing a dosed amount of chloride anions, compared to an electrolyte without chloride anions), indicating that the $\mathrm{CO}$ oxidation at the (111) terraces also proceeds according to the Langmuir-Hinshelwood type mechanism. A similar argument was used by Cuesta et al. ${ }^{31}$ to support the notion that the $\mathrm{CO}$ electro-oxidation reaction proceeds according to a Langmuir-Hinshelwood type mechanism.

Evaluation was made of the catalytic activity of different types of sites (such as the terraces and steps) on the same surface in a wide $\mathrm{pH}$ range (passing from extremely acid to extremely alkaline), using $\mathrm{Pt}(554)$ as an example (Figures 3 and 4). In $0.1 \mathrm{M} \mathrm{HClO}_{4}$, the main $\mathrm{CO}$ oxidation peak potential was at $\sim 0.763 \mathrm{~V}$ (Figure 3 ). Unfortunately, the CO oxidation peak resulted from the catalytic activity of all the surface sites, including (111) terraces and (110) steps. Therefore, it was not possible to identify the individual activities of the (111) terraces or the (110) steps, because the results overlapped. A value of $\sim 0.72$ $\mathrm{V}$ was obtained for $\mathrm{CO}$ oxidation at (110) step sites when there was no $\mathrm{CO}$ at the terraces (Figure 4). In the experiments using 0.1 M NaOH, with full $\mathrm{CO}$ coverage (Figure 3A, black line) or with CO release from steps (Figure 4D), it could be concluded that $\mathrm{CO}$ at the steps was only oxidized at $\sim 0.79 \mathrm{~V}$, which was $\sim 70 \mathrm{mV}$ higher than for the oxidation of $\mathrm{CO}$ at steps of the same surface in $0.1 \mathrm{M} \mathrm{HClO}_{4}$ (Figure $4 \mathrm{~B}$ ) or $0.1 \mathrm{M} \mathrm{H}_{2} \mathrm{SO}_{4}$ (Figure 4A). However, as shown in Figure 3A, the oxidation of $\mathrm{CO}$ at (111) terraces occurred at $0.61 \mathrm{~V}$ in $0.1 \mathrm{M} \mathrm{NaOH}$, which was $\sim 153 \mathrm{mV}$ lower than the value of $\sim 0.763 \mathrm{~V}$ observed in $0.1 \mathrm{MHClO}_{4}$. Hence, a change in the solution $\mathrm{pH}$, which altered the charge at the electrochemical interface and the absolute potential of the electrode, had contrasting (balancing) effects on the catalytic activity of the sites of a stepped surface (see Figure 6). These effects depended on the crystallographic orientation of the sites on the same catalyst surface, with improved catalytic activity at (111) terraces, but strong inhibition of catalytic activity at (110) steps. The fact that different facets at the same (stepped) 
surface present both different reactivity and different catalytic activity is well documented for both solid/gas ${ }^{67-69}$ and electrified electrode/aqueous ${ }^{38,39,42}$ interfaces. Here, we demonstrate experimentally exactly how a change in solution $\mathrm{pH}$ contributes to balancing the catalytic activity of active sites, depending on the crystallographic orientation (step sites and (111) terraces) at the same catalyst surface. Hence, the $\mathrm{pH}$ dependence of electrocatalysis of $\mathrm{CO}$ oxidation at Pt electrodes differs according to whether $\mathrm{CO}$ is bound at low coordinated sites or (111) terrace sites. This contrasting effect occurred at extremely high $\mathrm{pH}$, with the catalytic activities of all the sites improving when phosphate buffer ( $\mathrm{pH}$ 7.65) was used. In a previous study, we reported that a selective change in the surface composition of a $\operatorname{Pt}(s)-[(n-1)(111) \times(110)]$ stepped surface, such as modification of the (110) steps by $\mathrm{Ru}^{70}$, or changing the $\mathrm{Pt}(h k l) / \mathrm{CO}$ system from an acid (electro)chemical environment in which the $\mathrm{CO}$ adlayer was deposited to an alkaline solution in which it was oxidized ${ }^{71}$, resulted in selective promotion of CO oxidation only at the (111) terraces. In these cases, the catalytic activity towards this reaction of the other sites (such as steps/kinks) on the same Pt stepped surface remained unaffected. In the present case, it was found that the contrasting balances in activity of different sites caused by changing the (electro)chemical (solution) environment of a Pt catalyst was related to the type of site, and seemed to be influenced by the surface scale of the catalyst in question. From comparison of the voltammetric profiles for $\mathrm{CO}$ oxidation on shapecontrolled Pt nanoparticles in acid ${ }^{72}$ and alkaline ${ }^{73,74}$ solutions, it can be concluded that changing the solution $\mathrm{pH}$ from acidic to alkaline is accompanied by the promotion of all types of catalytic sites at nanoparticle surfaces. Hence, the contrasting balances in catalytic activity at low coordinated sites on extended Pt surfaces, compared to the (111) terraces, indicate that low coordinated sites on a stepped surface present different catalytic behavior, compared to low coordinated sites on a Pt nanoparticle.

The solution $\mathrm{pH}$ also appeared to have different effects on the $\mathrm{H}_{\mathrm{UPD}}$ binding energy, depending on the site at stepped Pt surfaces. Examination of the hydrogen region in the cyclic voltammograms of $\operatorname{Pt}(554)$ or $\operatorname{Pt}(544)$ obtained for solutions of all $\mathrm{pH}$ showed that the feature attributed to hydrogen discharging at steps shifted (on the RHE scale), while the potential region for hydrogen discharging at (111) terraces remained almost unchanged. Since the potential position of the HUPD peak directly reflects the HUPD binding energy at Pt surfaces, the hydrogen binding energy increases as the solution $\mathrm{pH}$ increases $^{49,75}$. In order to explain the shift in the H-steps peak, the existence of many 
species in the so-called hydrogen region has been proposed, such as $\mathrm{H}_{\mathrm{ads}}, \mathrm{O}_{\text {ads }}$, or $\mathrm{OH}$, with the composition varying according to solution $\mathrm{pH}^{50}$. As before, a change in solution $\mathrm{pH}$ consequently leads to alteration of the charge at the electrochemical interface and the absolute potential, accompanied by different energy balance for the adsorption/desorption of HUPD, depending on the crystallographic orientation of the sites at which such processes take place. Therefore, a change in solution $\mathrm{pH}$ (and electrode potential) seems to cause a non-homogeneous (or non-linear) alteration in the energies attributed to different types of sites at the catalyst surface.

\section{Conclusions}

This work presents an evaluation of the influence of oxyanions and $\mathrm{pH}$ on the catalytic activity of specific sites on stepped Pt surfaces. The findings can be summarized as follows:

$i$. Perchlorate, sulfate, and phosphate anions affect the overall catalytic activity of $\mathrm{Pt}(\mathrm{s})-$ $[(n-1)(111) \times(110)]$ and $\mathrm{Pt}(\mathrm{s})-[(n-1)(111) \times(100)]$ stepped Pt surfaces, according to the type of $\mathrm{CO}$ surface coverage. When $\mathrm{CO}$ adlayer oxidation started from a complete coverage, a shift to lower potential of the main $\mathrm{CO}$ oxidation peak was in agreement with weaker adsorption of anions. Oxyanions derived from the dissociation of perchloric, sulfuric, and phosphoric acids did not affect the intrinsic catalytic activity towards CO oxidation at steps, in the case of (110) and (100) orientations.

ii. The change from an extremely low $\mathrm{pH}$ electrolyte solution to one with an extremely high $\mathrm{pH}$ had contrasting effects on the catalytic activity of the different sites present on the same stepped Pt surface, with improved activity at (111) terraces, but evidence of inhibition of activity at the steps. This allowed a precise determination of how the $\mathrm{pH}$ of the solution influenced the balance of catalytic activity of sites at different facets of the same catalyst surface. This enabled us to identify the (111) terraces as the most active sites towards the $\mathrm{CO}$ electro-oxidation reaction at stepped $\mathrm{Pt}$ surfaces.

iii. Surface site release was only a hierarchical process for the $\operatorname{Pt}(\mathrm{s})-[(n-1)(111) \times(110)]$ series. In the case of the $\operatorname{Pt}(\mathrm{s})-[(n-1)(111) \times(100)]$ series, there was no hierarchy for surface site release, and (111) terrace and (100) steps were simultaneously free during the course of $\mathrm{CO}$ adlayer oxidation. In all cases, $\mathrm{CO}$ apparently behaved as an immobile species during its oxidation 


\section{Associated Content}

\section{Supporting Information}

Additional experimental data concerning the electrochemical results (cyclic voltammetry results for the blank and CO stripping) are provided (PDF).

Acknowledgements: M.J.S. Farias acknowledges financial support from PNPD/CAPES (Brazil). G.A.B.M. received a post-doctorate fellowship from CNPq (grant no. PDE 233268/2014-6). A.A.T. acknowledges support from CAPES (PROCAD 2013) and CNPq (grant no. 309066/2013-1). J.M.F. thanks MICINN (Project CTQ2016-76221-P) and GV (Project PROMETEOII/2014/013) for financial support. 


\section{References}

1. M. Boudart, in Adv. Catal., Eley, D. D.; Pines, H.; Weisz, P. B., Eds. Academic Press: 1969; Volume 20, pp 153-166.

2. M. Boudart, Ind. Eng. Chem. Fund., 1986, 25, 656-658.

3. R. A. Van Santen, Acc. Chem. Res., 2009, 42, 57-66.

4. $\quad$ M. T. M. Koper, Nanoscale, 2011, 3, 2054-2073.

5. R. Kavanagh, X.-M. Cao, W.-F. Lin, C. Hardacre and P. Hu, Angew. Chem. Int. Ed., 2012, 51, 1572-1575.

6. E. A. Monyoncho, S. N. Steinmann, C. Michel, E. A. Baranova, T. K. Woo and P. Sautet, ACS Catal., 2016, 6, 4894-4906.

7. M. A. Habib and J. O. M. Bockris, in Comprehensive Treatise of Electrochemistry: The Double Layer, eds. J. O. M. Bockris, B. E. Conway and E. Yeager, Springer US, Boston, MA, 1980, DOI: 10.1007/978-1-4615-6684-7_4, pp. 135-219.

8. B. Braunschweig and W. Daum, Langmuir, 2009, 25, 11112-11120.

9. A. Kolics and A. Wieckowski, J. Phys. Chem. B, 2001, 105, 2588-2595.

10. B. Braunschweig and A. Wieckowski, J. Electroanal. Chem., 2014, 716, 136-144.

11. T. Kondo, T. Masuda, N. Aoki and K. Uosaki, J. Phys. Chem. C, 2016, 120, 16118-16131.

12. V. Colic, M. D. Pohl, D. Scieszka and A. S. Bandarenka, Catal. Today, 2016, 262, 24-35.

13. Y. Shingaya and M. Ito, J. Electroanal. Chem., 1994, 372, 283-288.

14. Y. Sawatari, J. Inukai and M. Ito, J. Electron Spectrosc. Relat. Phenom., 1993, 64, 515-522.

15. G. A. Attard, A. Brew, K. Hunter, J. Sharman and E. Wright, Phys. Chem. Chem. Phys., 2014, 16, 13689-13698.

16. K. Kunimatsu, H. Hanawa, H. Uchida and M. Watanabe, J. Electroanal. Chem., 2009, 632, 109-119.

17. D. V. Tripkovic, D. Strmcnik, D. Van Der Vliet, V. Stamenkovic and N. M. Markovic, Faraday Discuss., 2008, 140, 25-40.

18. F. C. Nart, T. Iwasita and M. Weber, Electrochim. Acta, 1994, 39, 961-968.

19. F. C. Nart, T. Iwasita and M. Weber, Electrochim. Acta, 1994, 39, 2093-2096.

20. T. Iwasita, F. C. Nart, A. Rodes, E. Pastor and M. Weber, Electrochim. Acta, 1995, 40, 53-59.

21. F. C. Nart and T. Iwasita, J. Electroanal. Chem., 1992, 322, 289-300.

22. R. Buják and K. Varga, Electrochim. Acta, 2006, 52, 332-341.

23. N. Garcia-Araez, V. Climent, P. Rodriguez and J. M. Feliu, Langmuir, 2010, 26, 12408-12417.

24. Z. Su, V. Climent, J. Leitch, V. Zamlynny, J. M. Feliu and J. Lipkowski, Phys. Chem. Chem. Phys., 2010, 12, 15231-15239.

25. S. T. Howard, G. A. Attard and H. F. Lieberman, Chem. Phys. Lett., 1995, 238, 180-186.

26. V. Stamenkovic, K. C. Chou, G. A. Somorjai, P. N. Ross and N. M. Markovic, J. Phys. Chem. B, 2005, 109, 678-680.

27. E. Herrero, J. Mostany, J. M. Feliu and J. Lipkowski, J. Electroanal. Chem., 2002, 534, 79-89.

28. J. Mostany, P. Martínez, V. Climent, E. Herrero and J. M. Feliu, Electrochim. Acta, 2009, 54, 5836-5843. 
29. V. Climent, N. García-Araez, E. Herrero and J. Feliu, Russ. J. Electrochem., 2006, 42, 1145-1160.

30. E. Herrero, B. Álvarez, J. M. Feliu, S. Blais, Z. Radovic-Hrapovic and G. Jerkiewicz, J. Electroanal. Chem., 2004, 567, 139-149.

31. A. Cuesta, A. Couto, A. Rincón, M. C. Pérez, A. López-Cudero and C. Gutiérrez, J. Electroanal. Chem., 2006, 586, 184-195.

32. A. López-Cudero, A. Cuesta and C. Gutiérrez, J. Electroanal. Chem., 2003, 548, 109-119.

33. R. Rizo, E. Sitta, E. Herrero, V. Climent and J. M. Feliu, Electrochim. Acta, 2015, 162, 138-145.

34. R. Martínez-Hincapié, P. Sebastián-Pascual, V. Climent and J. M. Feliu, Electrochem. Commun., 2015, 58, 62-64.

35. A. Couto, A. Rincón, M. C. Pérez and C. Gutiérrez, Electrochim. Acta, 2001, 46, 1285-1296.

36. R. Gisbert, G. García and M. T. M. Koper, Electrochim. Acta, 2011, 56, 24432449.

37. J. S. Spendelow, J. D. Goodpaster, P. J. A. Kenis and A. Wieckowski, J. Phys. Chem. B, 2006, 110, 9545-9555.

38. J. S. Spendelow, Q. Xu, J. D. Goodpaster, P. J. A. Kenis and A. Wieckowski, J. Electrochem. Soc., 2007, 154, F238-F242.

39. G. García and M. T. M. Koper, Phys. Chem. Chem. Phys., 2008, 10, 3802-3811.

40. A. S. Bandarenka and M. T. M. Koper, J. Catal., 2013, 308, 11-24.

41. E. Herrero, Q. S. Chen, J. Hernández, S. G. Sun and J. M. Feliu, Phys. Chem. Chem. Phys., 2011, 13, 16762-16771.

42. G. García and M. T. M. Koper, J. Am. Chem. Soc., 2009, 131, 5384-5385.

43. M. J. S. Farias, G. A. Camara and J. M. Feliu, J. Phys. Chem. C, 2015, 119, 2027220282.

44. M. J. S. Farias, E. Herrero and J. M. Feliu, J. Phys. Chem. C, 2013, 117, 29032913.

45. García.G, P. Rodríguez, V. Rosca and M. T. M. Koper, Langmuir, 2009, 25, 13661-13666.

46. J. Clavilier, D. Armand, S. G. Sun and M. Petit, J. Electroanal. Chem., 1986, 205, 267-277.

47. B. Lang, R. W. Joyner and G. A. Somorjai, Surf. Sci., 1972, 30, 440-453.

48. J. Clavilier, K. El Achi and A. Rodes, Chem. Phys., 1990, 141, 1-14.

49. W. Sheng, Z. Zhuang, M. Gao, J. Zheng, J. G. Chen and Y. Yan, Nat. Commun., 2015, 6.

50. M. J. T. C. Van Der Niet, N. Garcia-Araez, J. Hernández, J. M. Feliu and M. T. M. Koper, Catal. Today, 2013, 202, 105-113.

51. K. Schwarz, B. Xu, Y. Yan and R. Sundararaman, Phys. Chem. Chem. Phys., 2016, 18, 16216-16223.

52. J. Mostany, E. Herrero, J. M. Feliu and J. Lipkowski, J. Phys. Chem. B, 2002, 106, 12787-12796.

53. A. Berná, V. Climent and J. M. Feliu, Electrochem. Commun., 2007, 9, 27892794.

54. R. Gisbert, G. García and M. T. M. Koper, Electrochim. Acta, 2010, 55, 79617968.

55. A. Ferre-Vilaplana, C. Buso-Rogero, J. M. Feliu and E. Herrero, J. Phys. Chem. C, 2016, 120, 11590-11597.

56. V. Climent and J. M. Feliu, J. Solid State Electrochem., 2011, 15, 1297-1315. 
57. R. Gómez, V. Climent, J. M. Feliu and M. J. Weaver, J. Phys. Chem. B, 2000, 104, 597-605.

58. N. Hoshi, A. Sakurada, S. Nakamura, S. Teruya, O. Koga and Y. Hori, J. Phys. Chem. B, 2002, 106, 1985-1990.

59. T. H. Lin and G. A. Somorjai, Surf. Sci., 1981, 107, 573-585.

60. B. Tränkenschuh, C. Papp, T. Fuhrmann, R. Denecke and H. P. Steinrück, Surf. Sci., 2007, 601, 1108-1117.

61. B. Tränkenschuh, N. Fritsche, T. Fuhrmann, C. Papp, J. F. Zhu, R. Denecke and H. P. Steinrück, J. Chem. Phys., 2006, 124.

62. L. Vattuone, L. Savio and M. Rocca, Surf. Sci. Rep., 2008, 63, 101-168.

63. M. J. S. Farias, A. A. Tanaka, G. Tremiliosi-Filho and J. M. Feliu, Electrochem. Commun., 2011, 13, 338-341.

64. R. Smoluchowski, Phys. Rev., 1941, 60, 661-674.

65. J. Y. Park, G. M. Sacha, M. Enachescu, D. F. Ogletree, R. A. Ribeiro, P. C. Canfield, C. J. Jenks, P. A. Thiel, J. J. Sáenz and M. Salmeron, Phys. Rev. Lett., 2005, 95, 136802.

66. C. Buso-Rogero, E. Herrero, J. Bandlow, A. Comas-Vives and T. Jacob, Phys. Chem. Chem. Phys., 2013, 15, 18671-18677.

67. R. J. Gale, M. Salmeron and G. A. Somorjai, Phys. Rev. Lett., 1977, 38, $1027-$ 1029.

68. M. Salmeron, R. J. Gale and G. A. Somorjai, J. Chem. Phys., 1977, 67, 53245334.

69. J. T. Yates Jr, J. Vac. Sci. Technol., 1995, 13, 1359-1367.

70. M. J. S. Farias, W. Cheuquepan, G. A. Camara and J. M. Feliu, ACS Catal., 2016, 6, 2997-3007.

71. M. J. S. Farias, C. Busó-Rogero, R. Gisbert, E. Herrero and J. M. Feliu, J. Phys. Chem. C, 2014, 118, 1925-1934.

72. J. Solla-Gullón, F. J. Vidal-Iglesias, E. Herrero, J. M. Feliu and A. Aldaz, Electrochem. Commun., 2006, 8, 189-194.

73. F. J. Vidal-Iglesias, R. M. Arán-Ais, J. Solla-Gullón, E. Herrero and J. M. Feliu, ACS Catalysis, 2012, 2, 901-910.

74. M. J. S. Farias, F. J. Vidal-Iglesias, J. Solla-Gullón, E. Herrero and J. M. Feliu, J. Electroanaly. Chem., 2014, 716, 16-22.

75. J. Zheng, W. Sheng, Z. Zhuang, B. Xu and Y. Yan, Sci. Adv., 2016, 2. 
Figure 1. Hard sphere models for two stepped surfaces with similar (111) terrace widths, but different types of steps. $\operatorname{Pt}(332)$ : Rectangles indicate steps with (111) orientation; triangles indicate steps with (110) orientation. $\operatorname{Pt}(322)$ indicates steps with (100) orientation. http://surfexp.fhi-berlin.mpg.de/

Figure 2. Cyclic voltammograms of stepped Pt surfaces in $0.1 \mathrm{M} \mathrm{H}_{2} \mathrm{SO}_{4}$ (black line), 0.1 $\mathrm{M} \mathrm{HClO}_{4}$ (red line), $\mathrm{pH} 7.65$ phosphate buffer solution (blue line), and $0.1 \mathrm{M} \mathrm{NaOH}$ (olive line). Data recorded at $0.05 \mathrm{~V} \mathrm{~s}^{-1}$.

Figure 3. $\mathrm{CO}$ adlayer stripping on stepped Pt surfaces in $0.1 \mathrm{M} \mathrm{NaOH}$ (black line), pH 7.65 phosphate buffer (red line), $0.1 \mathrm{M} \mathrm{HClO}_{4}$ (blue line), and $0.1 \mathrm{M} \mathrm{H}_{2} \mathrm{SO}_{4}$ (olive line). Data recorded at $0.05 \mathrm{~V} \mathrm{~s}^{-1}$.

Figure 4. CO oxidation at steps on stepped Pt surfaces for various electrolytes (indicated). Data overlapped with the blank cyclic voltammogram. Recorded at $0.05 \mathrm{~V} \mathrm{~s}^{-1}$.

Figure 5. CO oxidation at steps on stepped Pt surfaces for various electrolytes (indicated). Data overlapped with the blank cyclic voltammogram. Recorded at $0.05 \mathrm{~V} \mathrm{~s}^{-1}$.

Figure 6. Dependence of $\mathrm{CO}$ oxidation peak potential on solution $\mathrm{pH}$ for experiments with $\mathrm{Pt}(554)$ starting from a full $\mathrm{CO}$ adlayer and from $\mathrm{CO}$ adsorbed only at the steps. Data extracted from Figures 3 and 4.

Figure 7. CO oxidation at steps on stepped Pt surfaces for various electrolytes (indicated) in the presence of different amounts of chloride ions. Recorded at $0.05 \mathrm{~V} \mathrm{~s}^{-1}$.

Figure 8. Successive voltammograms collected during the oxidation of $\mathrm{CO}$ adlayers on $\mathrm{Pt}(332)$ and $\mathrm{Pt}(322)$ in $0.1 \mathrm{M} \mathrm{H}_{2} \mathrm{SO}_{4}$ and $0.1 \mathrm{M} \mathrm{HClO}_{4}$. Recorded at $0.05 \mathrm{~V} \mathrm{~s}^{-1}$. P.S. means potentiodynamic sweep.

Figure 9. Successive voltammograms collected during the oxidation of $\mathrm{CO}$ adlayers on $\mathrm{Pt}(554)$ and $\mathrm{Pt}(544)$ in $0.1 \mathrm{M} \mathrm{H}_{2} \mathrm{SO}_{4}$. Recorded at $0.05 \mathrm{~V} \mathrm{~s}^{-1}$. P.S. means potentiodynamic sweep. 
Figures
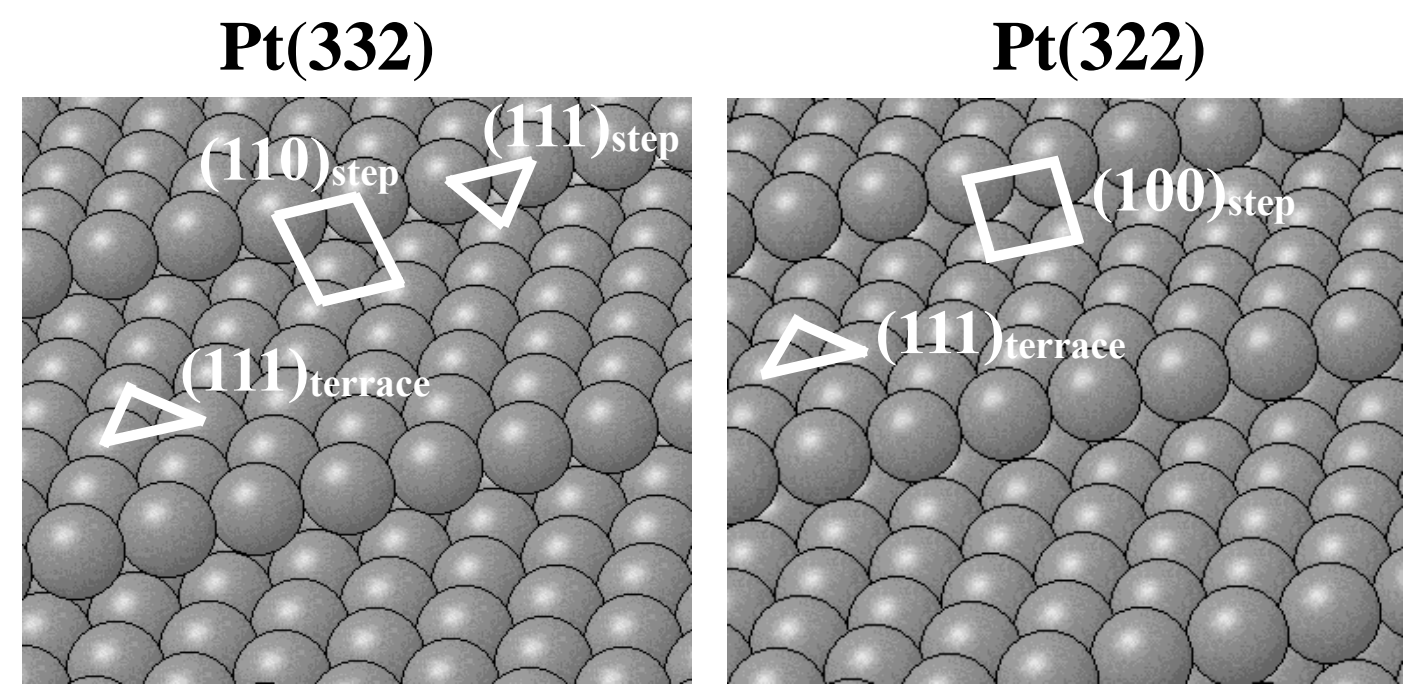

Figure 1. 

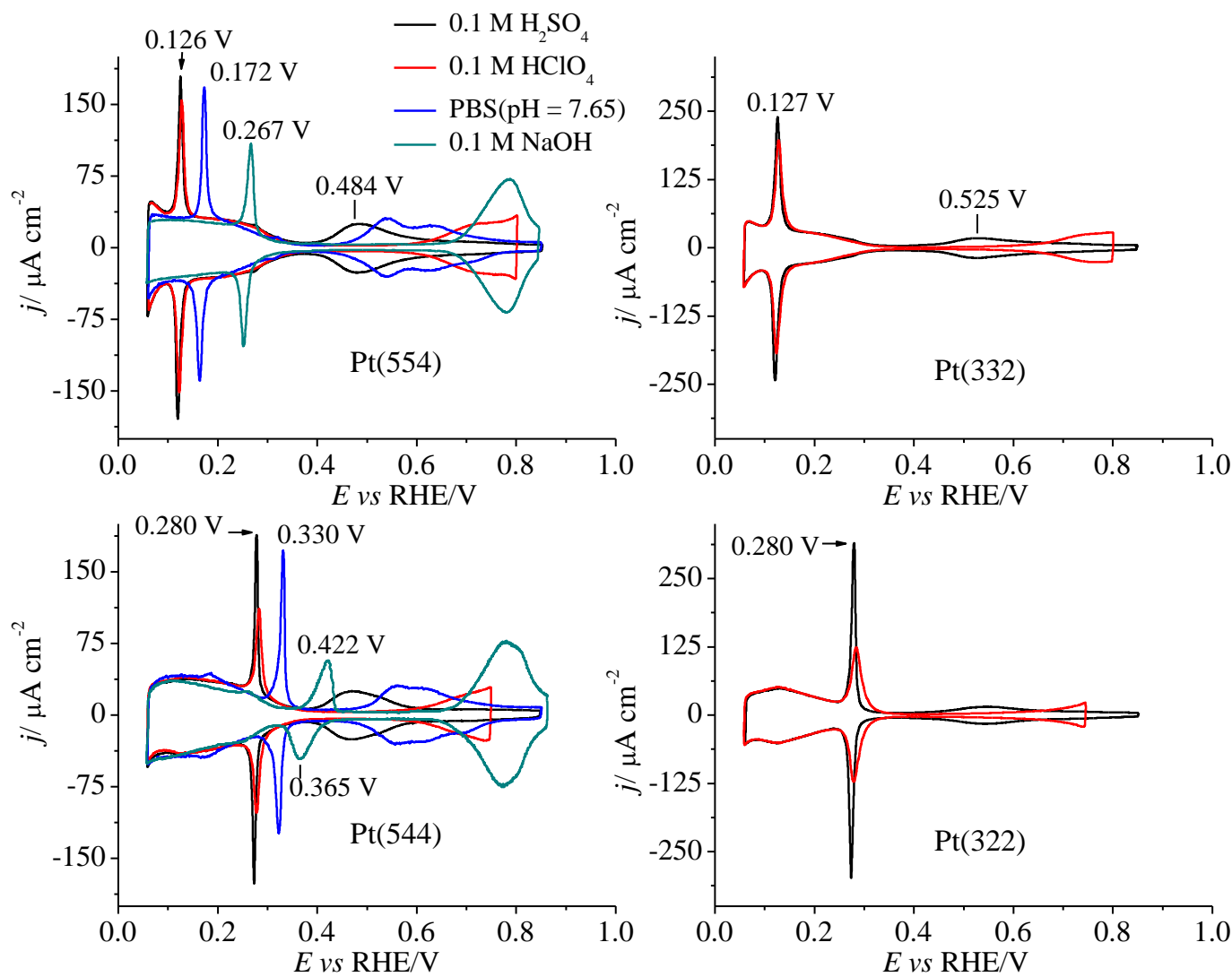

Figure 2. 


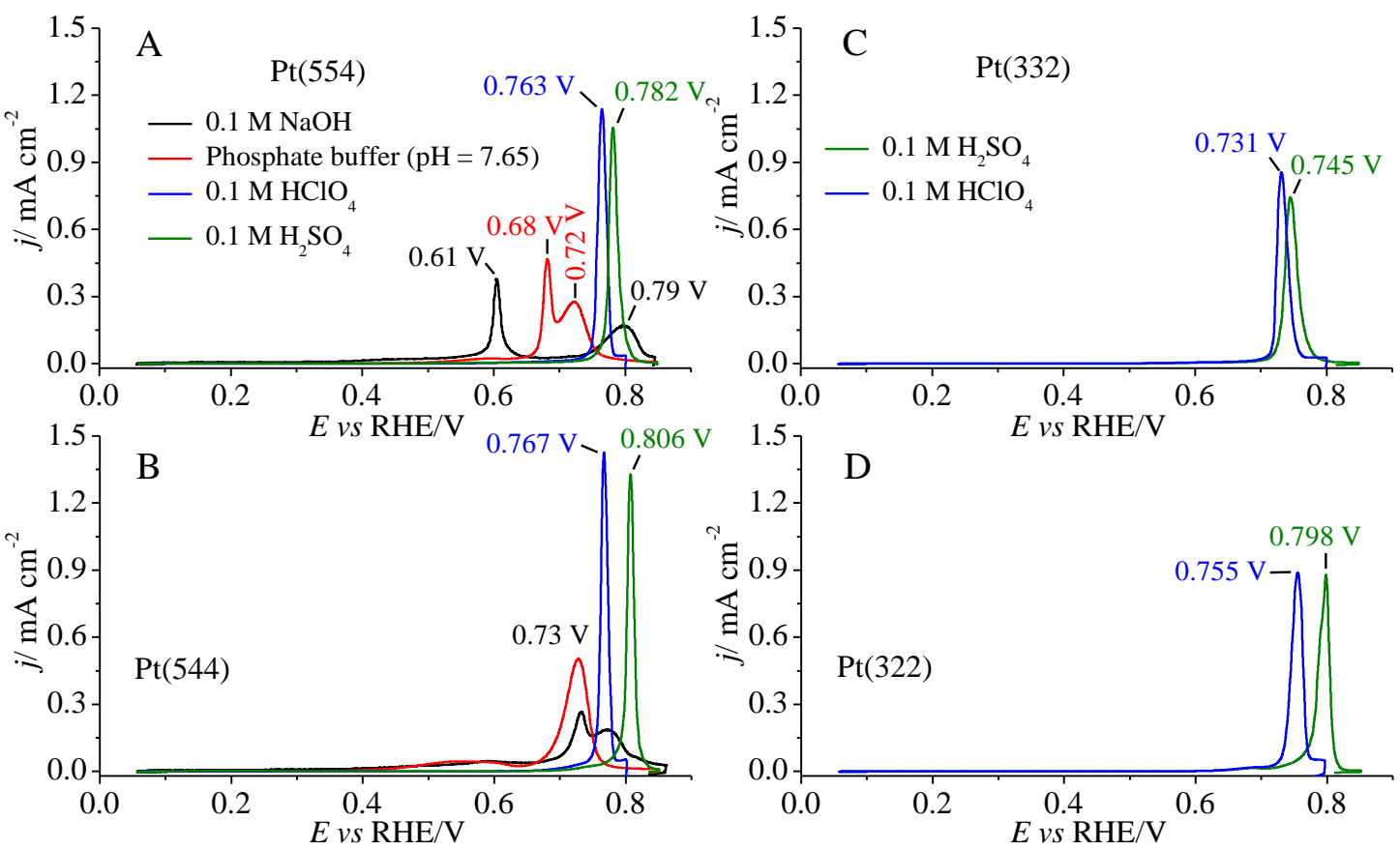

\section{Figure 3.}



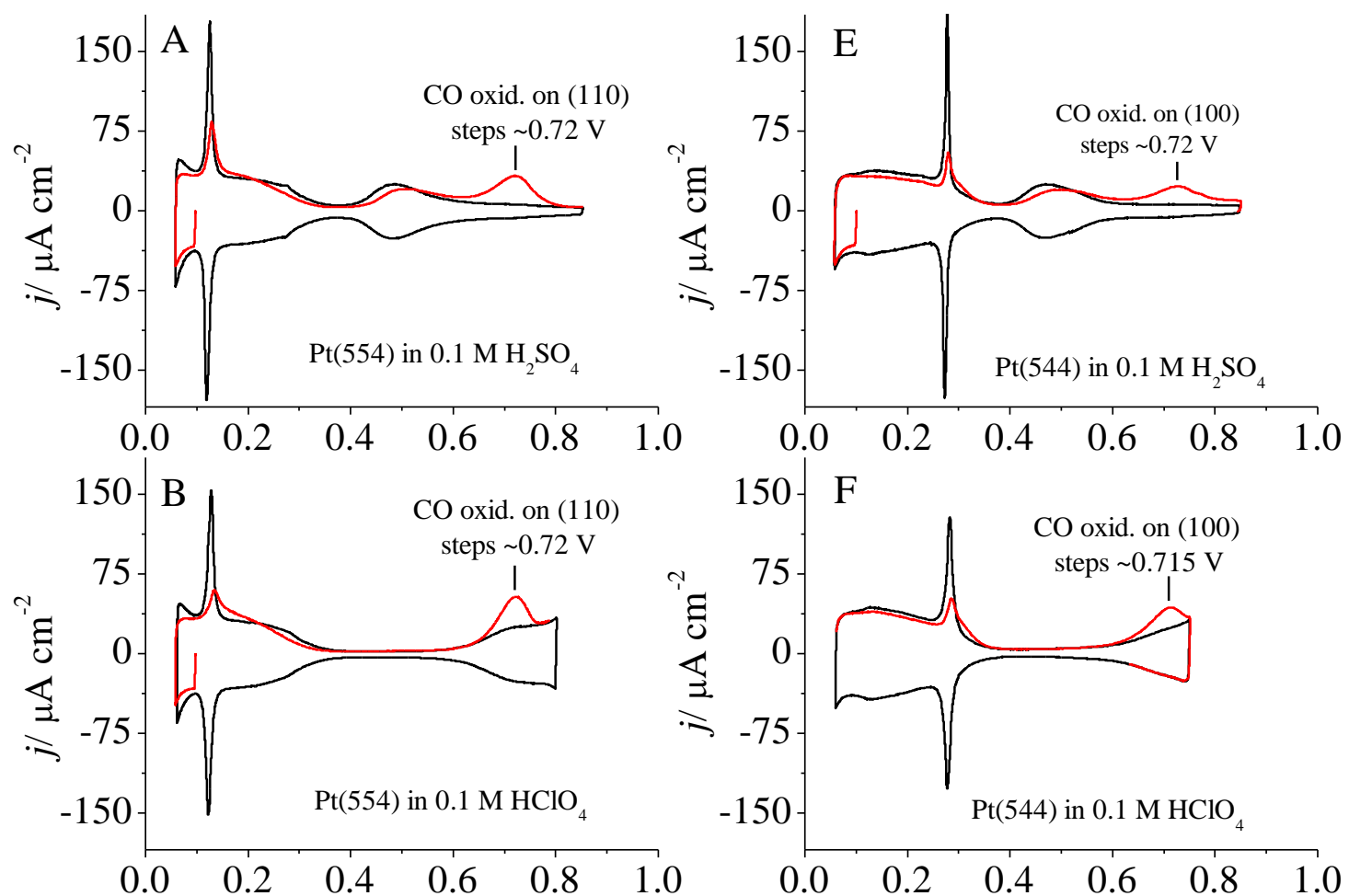

$150-\mathrm{F}$
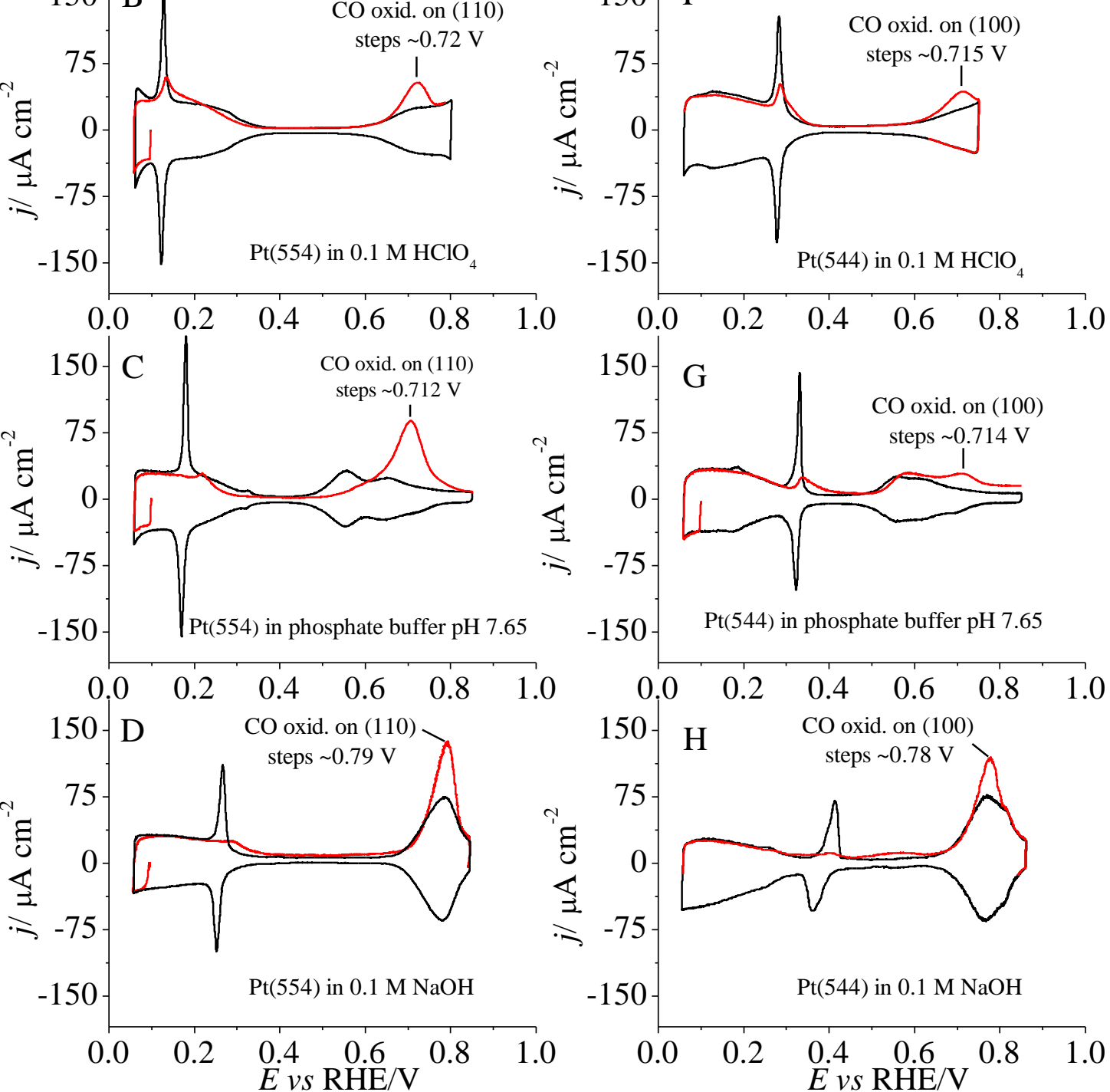

Figure 4. 

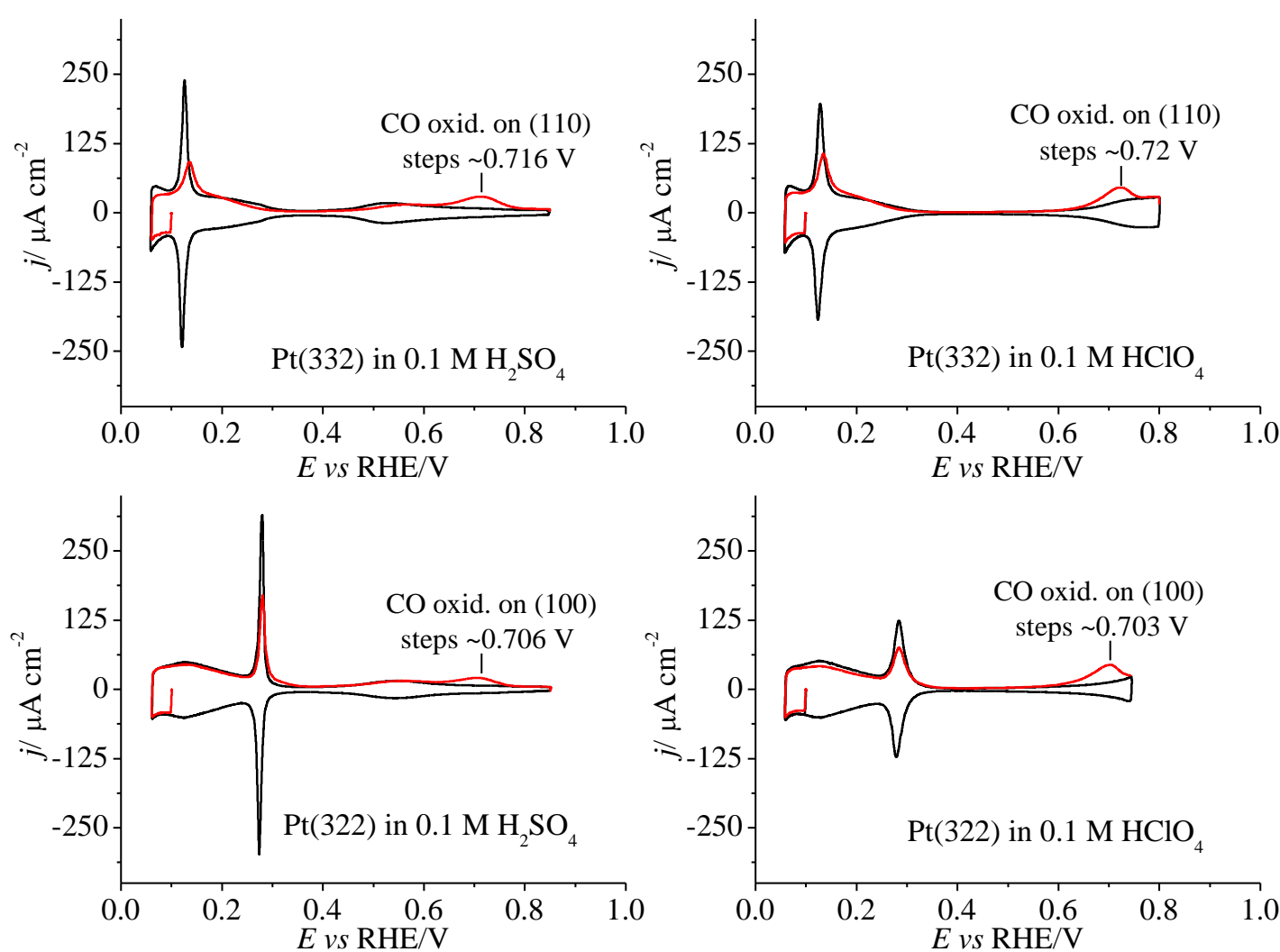

Figure 5. 


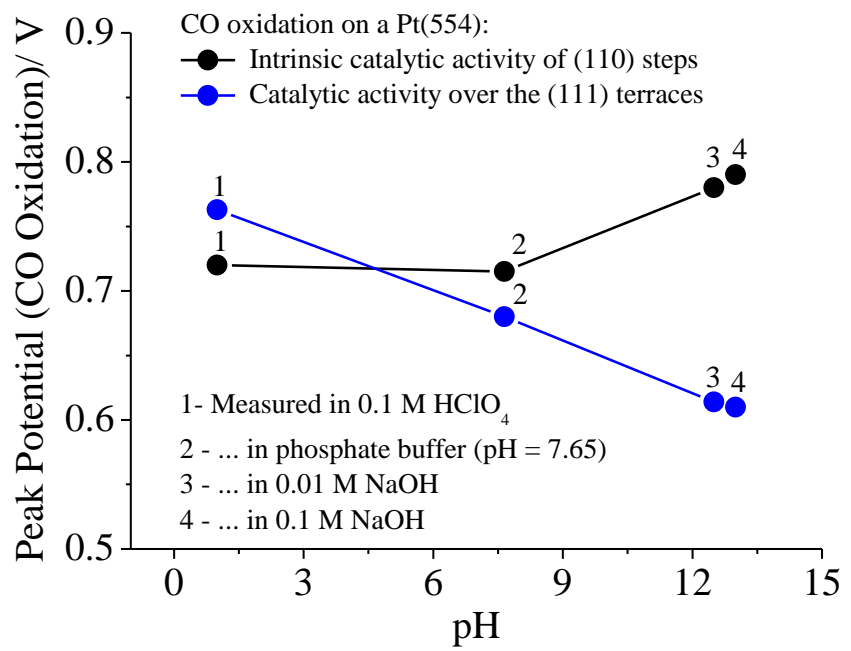

Figure 6. 

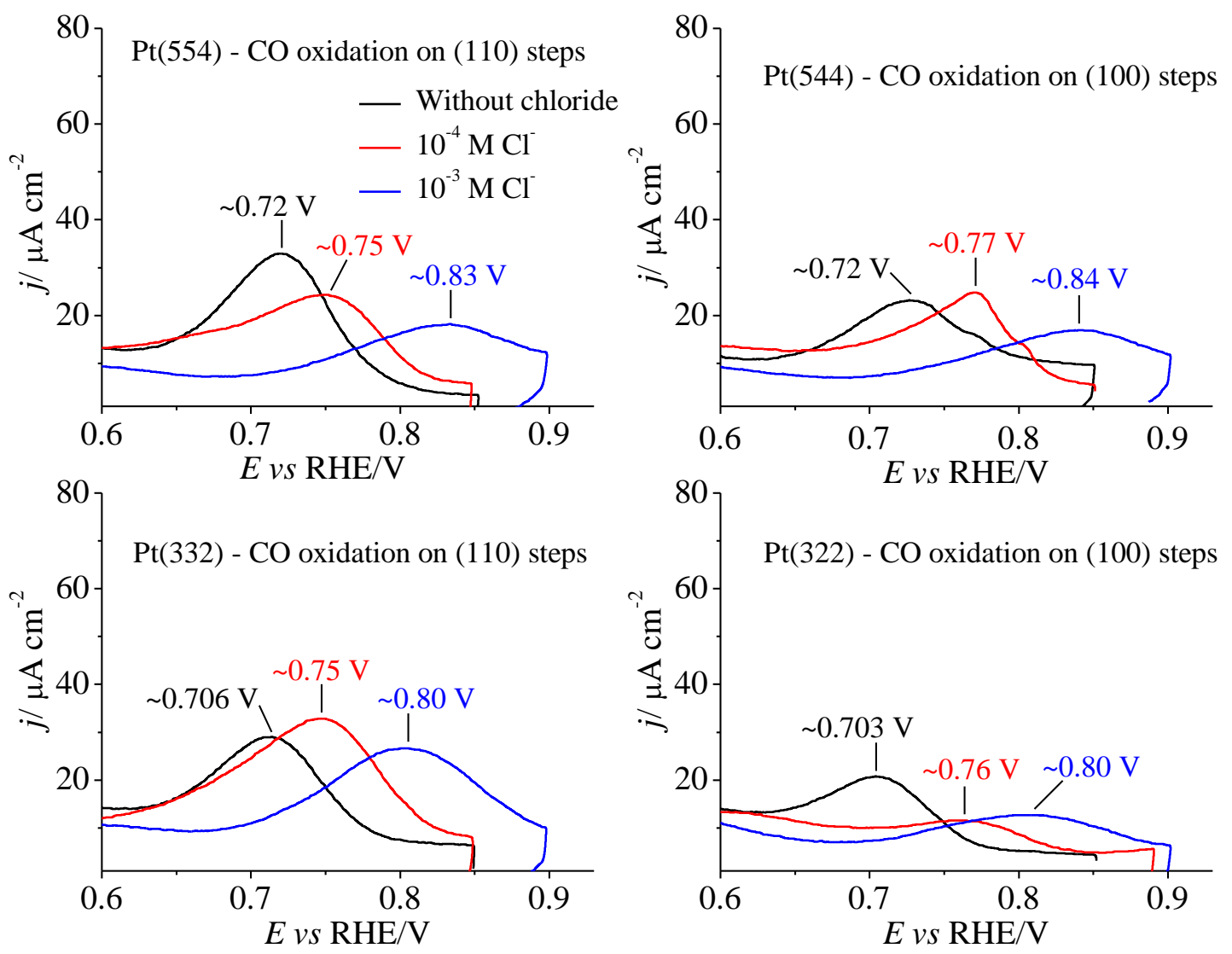

\section{Figure 7.}



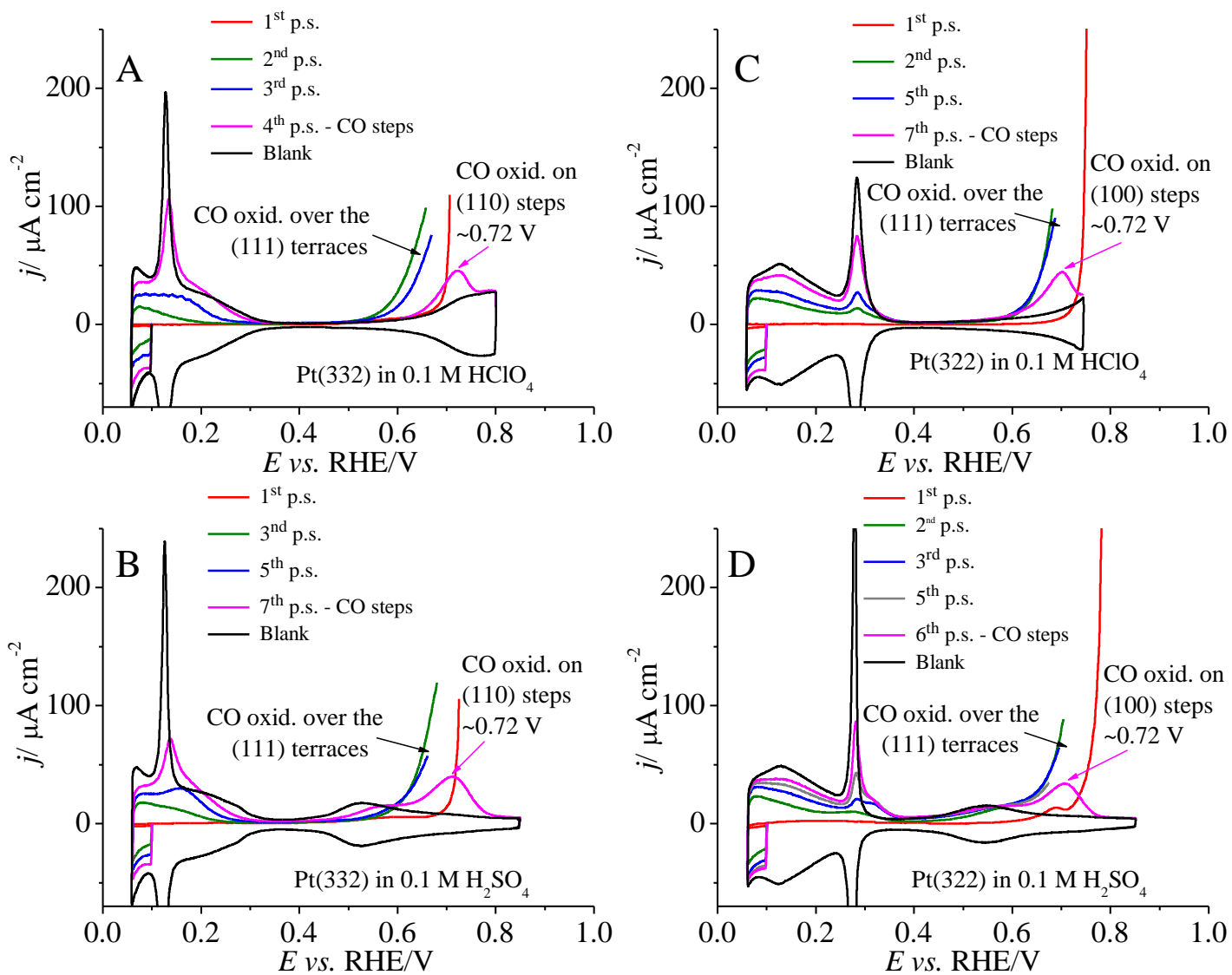

Figure 8. 

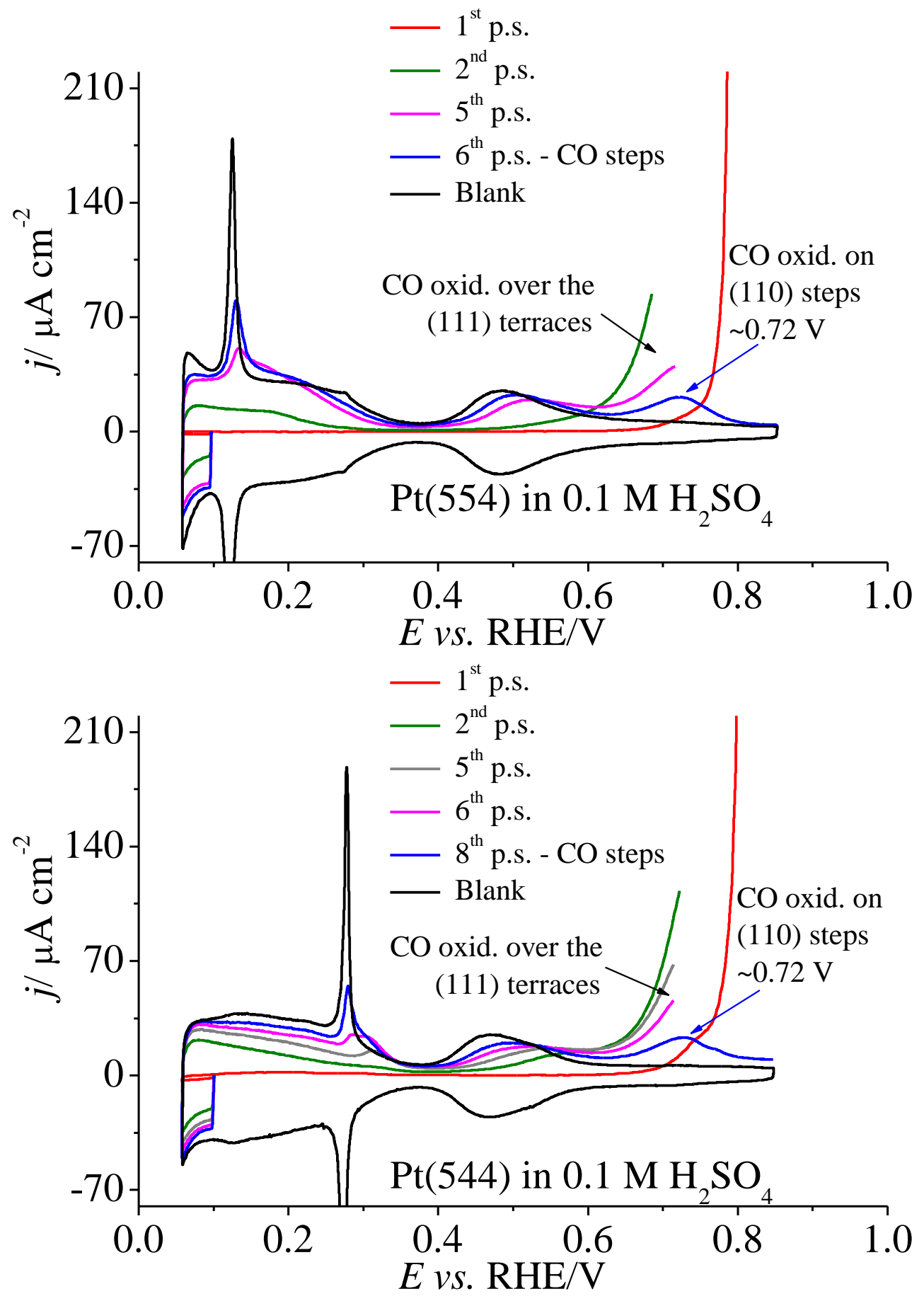

Figure 9. 